\title{
High Performance Waste-Derived Filler/Carbon Black Reinforced Guayule Natural Rubber Composites
}

Cindy S. Barrera ${ }^{\mathrm{a}}$, Katrina Cornish ${ }^{\mathrm{a} \mathrm{b}^{*}}$

${ }^{a}$ Food, Agricultural and Biological Engineering, Ohio Agricultural Research and Development Center, The Ohio State University, Wooster, Ohio, USA.

${ }^{b}$ Horticulture and Crop Science, Ohio Agricultural Research and Development Center, The Ohio State University, Wooster, Ohio, USA.

*Corresponding author: Katrina Cornish, Williams Hall, 1680 Madison Avenue, Wooster, Ohio 44691, USA. Tel: 330-263-3982 Fax: 330-263-3887 E-mail: cornish.19@osu.edu 


\title{
Graphical Abstract
}

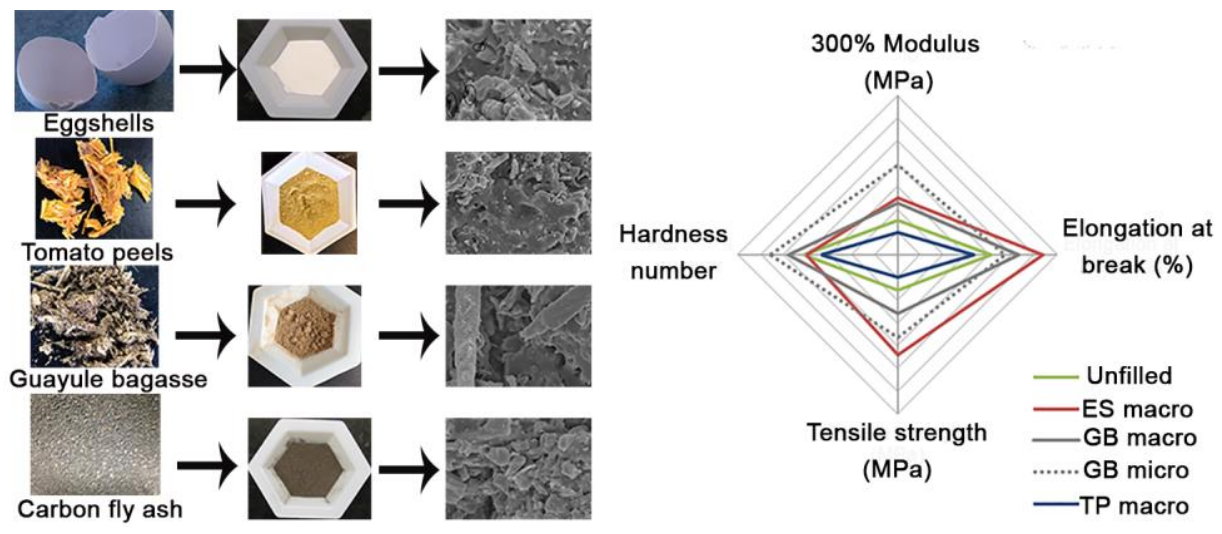

\begin{abstract}
Guayule rubber (GNR) is an alternative source of natural rubber that does not crossreact with Type I latex allergy because it does not contain any proteins which can be recognized by antibodies raised against Hevea brasiliensis allergens. To advance the commercialization of this elastomer and diversify sources of natural rubber, efficient reinforcement of GNR is required to match the physical properties of vulcanized materials made from Hevea natural rubber in specific products. Superior or comparable reinforcement to that of carbon black N330, was achieved by partial replacement of carbon black with 5 and $10 \mathrm{phr}$ of waste-derived material. Out of several waste-
\end{abstract}


derived fillers tested, micro sized eggshells showed remarkable reinforcing potential for GNR. Hybrid carbon black/micro sized eggshells/GNR composites (up to $20 \mathrm{phr}$ micro sized eggshells), had increased tensile strength, and elongation at break, while maintaining similar values of $300 \%$ modulus and hardness to those achieved by carbon black/GNR composites. Hierarchical cluster analysis partitioned the data into six groups of composites having statistically similar properties within each group. Composites containing 5-20 phr of micro sized eggshells were clustered in a separate group due to their unique combination of high tensile strength and flexibility. The superior reinforcement may reflect a combined synergistic reinforcing effect of carbon black particles, which possess a strong polymer-filler interaction, with the formation of a unique network between the GNR and the waste-derived materials, not attained with Hevea brasiliensis natural rubber.

Keywords: Natural rubber; Guayule; Waste-derived; Fillers; Reinforcing.

\section{Introduction}

Natural rubber (NR) is the only large scale, bio-based material among rubbers, and has a more environmentally-friendly production system than synthetic rubbers (Rasutis et al., 2015). NRs possess properties, such as malleability under cold temperatures, heat dispersion and strain induced crystallization among others (Chenal et al., 2007; Steinbüchel, 2003; Visakh et al., 2012), which cannot be matched by synthetic counterparts. In 2014, global NR consumption reached 12.159 million tons, nearly a 6.8\% increase from the previous year (International Rubber Study Group IRSG, 2015), and consumption is expected to continually increase due to rising demands from emerging economies such as China, India and Brazil. World NR consumption is expected to be 17 million metric tons by 2023 (International Rubber Study Group IRSG, 2014). Despite of being produced by over 2,500 plant species, commercial NR is obtained almost exclusively from the tropically-grown para rubber tree (Hevea brasiliensis)(Van Beilen and Poirier, 2007).

Parthenium argentatum Gray, commonly known as guayule, stands out as a promising alternative source of natural rubber (Cornish, 2001; Ray et al., 2005). This shrub, native to the Chihuahuan 
desert of Texas and North Central Mexico, produces high quality rubber comparable to hevea rubber (HNR) in terms of cis-1,4-polyisoprene content and molecular weight distribution (Castillo et al., 1979; Ponciano et al., 2012). However, important differences in the amount of non-rubber components have been identified between these two materials (Cornish, 2001; McMahan et al., 2015). Non-rubber constituents, such as proteins and lipids, contribute to rubber vulcanization behavior, and influence physical and chemical properties, particularly affecting the rate of crystallization when the material is under strain (Choi and Roland, 1997; McMahan et al., 2015). Differences in macromolecular structure also affect rubber compounding and product performance (Rensch et al., 1986).

GNR proteins do not crossreact with antibodies raised against Hevea latex proteins (Carey et al., 1995; Hamilton and Cornish, 2010; Siler and Cornish, 1995, 1994; Siler et al., 1996). Also, GNR possesses only $1 \%$ of the protein in HNR and $90 \%$ of these GNR trace proteins is a single protein, a nonallergenic cytochrome P450 oxidase making GNR particularly attractive for the production of elastomeric medical products.

GNR not only has lower protein content than HNR, but also contains relatively high levels of resin that can act as plasticizer and affect the resistance to deformation of the material (Schloman, 2005). The lower protein and higher resin content result in lower curing rates, lower oxidative stability and lower mechanical properties, compared to HNR, when the same cure package is used. Therefore, adjustments must be made to the vulcanization chemistry and to process parameters for GNR to achieve similar vulcanization kinetics and mechanical properties to HNR in any specific product application (Ray et al., 2010; Schloman, 2005).

Particulate materials (fillers) have been used for decades for the reinforcement, improvement of processing parameters, or dilution of NR and other elastomers (Donnet, 2003; Kohls and Beaucage, 2002). Carbon black is the oldest, and most widely used and studied, filler for rubber compounds due to its excellent reinforcing characteristics (Fröhlich et al., 2005; Kohls and Beaucage, 2002; Leblanc, 2002). However, carbon black is derived from petroleum, making this a non-renewable source. Carbon black has also been used to reinforce GNR (Porter and Stephens, 1979; Ramos-De Valle and Ramirez, 1982). 
Waste-derived, bio-based materials possess a great number of potential applications, including their use as fillers in rubber composites (Bras et al., 2010; Pasquini et al., 2010). Many such materials are continuously available in high volumes, and can help to improve the sustainability of rubber products by replacing or reducing the amount of petroleum-derived carbon black (Angellier et al., 2005; Barrera and Cornish, 2015; Gopalan Nair and Dufresne, 2003). Other potential benefits associated with the use of waste-derived materials include valorization of these residues, reduction of disposal cost, and reduction of the final cost of polymer products.

The efficacy of the fillers depends on parameters related to their characteristics, including particle size, structure and functionality, and also parameters related to the specific rubber and processing conditions being used (Ahmadi and Shojaei, 2013; Fröhlich et al., 2005). The objective of this study was to investigate the effect of different low cost, waste-derived fillers, as partial or full replacements of carbon black, on the mechanical properties of GNR composites under constant processing conditions.

\section{Material and methods}

\subsection{Materials}

GNR was obtained by drying guayule rubber latex (GNRL) for 48 hours at $50^{\circ} \mathrm{C}$ using a reflow oven, HVC 70 series, Conceptronic Inc. (Portsmouth, NH). Guayule rubber latex was extracted as described (Cornish, 1996), from fresh guayule shrub grown in Arizona. Compounding chemicals, namely, zinc oxide, stearic acid, sulfur, the vulcanization accelerator TBBS, and carbon black N330 (mean particle size: $108 \mathrm{~nm}$, SD: $31.42 \mathrm{~nm}$ ), were purchased from HB chemicals (Twinsburg, $\mathrm{OH}$ ). The waste filler raw materials were generously donated as follows: eggshells (ES) by Troyer's Home Pantry (Apple Creek, OH), carbon fly ash (CFA) by Cargill Salt (Akron, $\mathrm{OH}$ ), processing tomato peels (TP) by Hirzel Canning Co \& Farms (Toledo, $\mathrm{OH}$ ), and guayule bagasse (GB) was generated as a co-product of latex extraction. 


\subsection{Composites Preparation}

Fillers were prepared as described (Barrera and Cornish, 2015). A series of milling and sieving was used to obtain macro (diameter (d) of $300 \mu \mathrm{m}-38 \mu \mathrm{m}$ ) and micro (d of $38 \mu \mathrm{m}-100 \mathrm{~nm}$ ) sized particles from the waste-derived materials. Particle size distributions were determined using a Particle size analyzer LA-950V2, Horiba Scientific (Irvine, CA). Filler bulk densities were determined by weighing a known volume of each filler and calculating the bulk density as mass/volume occupied.

The effect of different types of waste-derived fillers, particle size and filler loading, were determined using a standard compound formulation initially containing $35 \mathrm{phr}$ (parts per hundred rubber) of carbon black N330 with no other filler (Table 1). Carbon black was gradually replaced by each specific waste-derived filler until no carbon black remained. The processing conditions for rubber compounding and curing matched those previously described (Barrera and Cornish, 2015).

\subsection{Materials Characterization}

\subsubsection{Mechanical Properties}

Tensile properties were measured according to ASTM D412 (ASTM International, 2013a),along the grain direction with a crosshead speed of $500 \mathrm{~mm} / \mathrm{min}$ at $23^{\circ} \mathrm{C}$. Tensile test was done using a tensiometer, Model 3366, Instron (Norwood, MA), with the Bluehill v. 2.26 software package. Five dumbbell specimens of each composite, cut using ASTM D412 Die C, were tested. The samples were conditioned at $23 \pm 2^{\circ} \mathrm{C}$ and at a relative humidity of $50 \pm 5 \%$ for at least 24 hours prior to assessment of tensile properties. The resulting properties of these composites (300\% modulus, tensile strength and elongation at break) were compared. Hardness was determined according to ASTM D 2240 (ASTM International, 2010a), using a Shore A, Ergo style durometer, model 408, PTC Instruments, (Los Angeles, CA) with an operating stand type 2. A mass of one $\mathrm{kg}$, securely affixed to the durometer and centered on the axis of the indentor was used in order to improve repeatability. 


\subsubsection{Scanning Electron Microscopy (SEM)}

The morphology of the different materials and dispersion of the fillers within the polymer matrices was investigated using a Hitachi S-3500N scanning electron microscope (Tokyo, Japan), operated under high vacuum. After tensile testing, cross sections of each composite sample at the fracture surface were cut and washed with a $70 \%$ aqueous ethanol solution, to eliminate surface contamination. The samples were sputter-coated with a thin layer of platinum $(0.2 \mathrm{~K} \AA)$ by an Anatech Hummer 6.2 Sputtering system prior to analysis in order to improve their conductivity, allowed to dry, and then imaged.

\subsubsection{Swelling Properties}

Swelling measurements were performed on samples of $10 \mathrm{~mm} \times 10 \mathrm{~mm} \times 2 \mathrm{~mm}$. The initial weight of the dry samples was recorded to an accuracy of $0.1 \mathrm{mg}$. Samples were immersed in toluene and kept at $25^{\circ} \mathrm{C}$. The samples were periodically removed from the test bottles, weighed and immediately replaced in the bottles. This procedure was continued until no change in sample weight was noted. The swelling ratio of the samples was calculated as follows:

$$
\text { Swelling ratio }=\frac{\left(\mathrm{W}_{t}-\mathrm{W}_{0}\right)}{\mathrm{W}_{0}}
$$

Where $\mathrm{W}_{0}$ and $\mathrm{W}_{\mathrm{t}}$ are the weights of the samples before and after a time $\mathrm{t}$ of immersion, respectively. The value of swelling ratio of each composite was the average of three specimens. Crosslink density of the sample was calculated using the Flory-Rehner equation (ASTM International, 2013b).

$$
v_{e}=\frac{-\left[\ln \left(1-\mathrm{V}_{r}\right)+\mathrm{V}_{r}+x_{1} \mathrm{~V}_{r}^{2}\right]}{\left[\mathrm{V}_{1}\left(\mathrm{~V}_{r}^{1 / 3}-\mathrm{V}_{r}\right) / 2\right]}
$$

Where $x_{1}$ is the polymer-solvent interaction parameter $(0.393)$ and $\mathrm{V}_{1}$ is the molar volume of the solvent $\left(106.2 \mathrm{~cm}^{3} / \mathrm{g}\right.$ mole) (Sheehan and Bisio, 1966). $V_{r}$ is the volume fraction of polymer in a swollen network in equilibrium with solvent, and was calculated as (ASTM International, 2013b): 


$$
\mathrm{V}_{r}=\frac{\mathrm{W}_{\mathrm{r}} / \rho_{\mathrm{r}}}{\mathrm{W}_{\mathrm{r}} / \rho_{\mathrm{r}}+\mathrm{W}_{\mathrm{s}} / \rho_{\mathrm{s}}}
$$

Where $\mathrm{W}_{\mathrm{r}}$ and $\mathrm{W}_{\mathrm{s}}$ are weights of the dried sample and solvent absorbed by the sample, respectively. $\rho_{\mathrm{r}}$ and $\rho_{\mathrm{s}}$ are the density of the rubber compound and solvent respectively. $\rho_{\mathrm{r}}$ was calculated as described (ASTM International, 2013b).

\subsection{Statistical Analysis}

Statistical significance of the independent variables, i.e. filler type, particle size, and filler loading was determined by analysis of variance (ANOVA) with a significance level $\alpha$ of 0.05 using the software JPM v.11 from SAS. Multiple means comparison Tukey-Kramer tests, at a significance level $\alpha$ of 0.05 , were performed, to determine statistical differences between composites properties.

Composites with similar mechanical properties were grouped through cluster analysis using Vegan package (Vegan v. 2.3-0) implemented in R (R Core Team, 2014). In this multivariate analysis, every sample was described by results obtained from the four different response properties: i.e. $300 \%$ modulus, tensile strength, elongation at break, and hardness number. Euclidian distance was used to measure the similarity between the treatments. Ward's method was used as the linkage method. The data were standardized so that the variation extent of each response variable had an equivalent contribution to the formation of the classification.

\section{Results}

\subsection{Characterization of Fillers}

Significant differences were observed among the bulk densities of the waste derived fillers. GB possessed the lowest bulk density among the fillers used, both at the macro and micro scale, while ES particles possessed the highest (Table 2). In general, macro sized particles had a higher bulk density than the micro sized material. Carbon black's bulk density was significantly different from the bulk density of all other fillers, except the micro sized GB. Filler loading in the composites was measured based on weight of the materials, therefore, substantially larger volumes of material 
were needed for the preparation of the composites with lower bulk density for similar weight loadings.

Variations in particle size distributions also were observed among the different materials (Fig. 1). The largest mean particle size and broadest distribution was in the GB fillers for both size ranges. CFA had the smallest mean particle size for both macro and micro size ranges. These discrepancies have important implications in the final characteristics of the composites. Particles in the size range of $38 \mu \mathrm{m}$ or smaller were present in the macro sized particle distributions and were considered in the interpretations of the results. However, these small portions of material did not seem to drastically affect the overall composite properties.

A variety of particle shapes and complex structures were identified among the fillers. TP presented different particle structure at the macro and micro size scale. At a micro scale, TP particles (Fig. 2a) were agglomerates of small granules similar to the carbon black structure (Fig. 2b). In contrast, macro sized TP had a laminar shape (Fig. 2c). CFA and ES (Figs. 2d, 2e) both were block like particles with irregular contours; however, CFA particles had a more porous structure than the ES particles. The GB filler particles had the elongated, cylindrical shape characteristic of cellulosic fibers (Fig. 2f).

\subsection{Mechanical properties of composites}

Filler loading, filler type and particle size, had significant effects on all the measured mechanical properties of GNR composites. Superior or comparable mechanical properties to those of carbon black filled composites were achieved by partial replacement of carbon black with low loadings (5 and 10 phr) of all waste-derived fillers (Fig. 3). Remarkably, the micro sized ES particles, in combination with carbon black, showed reinforcement beyond carbon black alone. The addition of micro sized ES up to $20 \mathrm{phr}$ (57\% replacement of carbon black in the composite), improved tensile strength and elongation while maintaining similar values of $300 \%$ modulus and hardness to those achieved by carbon black alone. In addition, 5 phr of micro sized TP and CFA and $5 \mathrm{phr}$ of macro sized GB had tensile strength of $25.79 \pm 0.08 \mathrm{MPa}, 24.05 \pm 0.26 \mathrm{MPa}$ and $26.28 \pm 0.41$ 
MPa respectively, significantly higher than composites manufactured with carbon black alone $(21.3 \pm 0.75 \mathrm{MPa})$.

Composites containing $5 \mathrm{phr}$ of macro sized CFA, TP and GB, 10 phr of macro sized GB and TP, or 5 phr of micro sized CFA, had significantly higher $300 \%$ modulus than composites with carbon black alone. Nearly $94 \%$ of composites containing 5 and $10 \mathrm{phr}$ of macro and micro sized wastederived fillers had significantly higher hardness numbers that the carbon black composites.

In general, as the amount of waste-derived filler in the composite increased above $5 \mathrm{phr}$ and the amount of carbon black in the composites decreased below $30 \mathrm{phr}$, tensile strength, $300 \%$ modulus and hardness decreased while elongation at break increased (Fig. 3). However, the mechanical properties of unfilled vulcanized GNR were considerably improved with the incorporation of the different waste-derived fillers alone (Fig. 4). All the composites made with $35 \mathrm{phr}$ of waste-derived fillers (no carbon black), except those made with $35 \mathrm{phr}$ of macro sized TP and GB, had significantly higher tensile strength than unfilled vulcanized rubber $(7.07 \pm 0.41 \mathrm{MPa})$. Furthermore, composites manufactured with 35 phr of micro sized GB and ES presented significantly higher values of $300 \%$ modulus, while significantly higher values of hardness were obtained for composites containing $35 \mathrm{phr}$ of micro sized GB.

Composites made only with waste-derived fillers had significant lower $300 \%$ modulus, tensile strength and hardness than carbon black filled composites (Fig 4). Nonetheless, composites containing $35 \mathrm{phr}$ of micro sized TP had the highest tensile strength (18.7MPa) among the $35 \mathrm{phr}$ waste-derived composites, only $12 \%$ lower than carbon black composites. In addition, elongation at break of 35 phr micro sized TP was 0.6 times higher than elongation of carbon black composites and very close values of hardness.

\subsection{Composite Morphology}

The SEM's of composite morphology (Fig. 5) indicate that, upon fracture, particles remained embedded in the rubber, especially in ES and TP composites (Fig. 5b and d). Polymer strings connecting the filler to the rubber matrix, uneven polymer surfaces around the filler and roughness of the particles suggest relatively good interfacial adhesion between some of the fillers and GNR. 
Furthermore, uniform dispersion of the fillers within the composites, without agglomeration, was attained at all loadings including $35 \mathrm{phr}$ (Fig. 5) (SEM's for lower loadings are not shown).

\subsection{Swelling behavior}

All the composites had a rapid weight gain during the first $3 \mathrm{~h}$ in toluene, but then the sorption rate decreased reaching a plateau (Fig. 6) (swelling curves of composites containing 10 and $20 \mathrm{phr}$ of waste-derived fillers are not shown). Variations of swelling ratio at equilibrium and crosslink density were observed among the different guayule rubber compounds (Table 3). Composites containing $5 \mathrm{phr}$ of waste-derived fillers had very similar swelling behavior to composites containing only carbon black.

Replacement of carbon black with waste-derived filler in the composites led to an increase in swelling ratio and a decrease in crosslink density. The largest swelling ratios were achieved by unfilled guayule compound and composites containing $35 \mathrm{phr}$ of waste-derived filler as full replacement of carbon black. Nevertheless, the addition of macro and micro sized TP and ES up to $35 \mathrm{phr}$ (no carbon black) significantly reduced the swelling of the guayule rubber compounds (Table 3). Most of the composites containing micro sized filler had higher swelling ration than macro sized composites at the same loading with the same filler.

\subsection{Cluster analysis}

Analysis of overall properties led to the classification of the composites into six groups with different characteristics (Fig. 7). Composites made with $35 \mathrm{phr}$ of waste-derived fillers, and the unfilled vulcanized rubber sample, were grouped within clusters 1 and 2. Each property cluster was then plotted as a radar plot (Fig. 8). Composites in cluster 1 (Fig.8 first row, left) included composites with relatively low values of $300 \%$ modulus (less than $1.7 \mathrm{MPa}$ ), low hardness (hardness number less than 40), medium values of elongation at break (1550\% - 1820\%), and the lowest tensile strength among the composites . Composites grouped in cluster 2 (Fig.8 first row, right) possessed the lowest values of $300 \%$ modulus, the lowest hardness, the highest elongation 
at break, and low tensile strength (less than $13 \mathrm{MPa}$ ). Based on the mechanical properties, these clusters are more similar to each other than to any of the other clusters (Fig. 7), and these composites achieved the lowest performance properties of any of the composite groupings.

Cluster 3 (Fig.8 second row, left) is the largest group of samples with similar performance properties and contains mostly composites manufactured with $5 \mathrm{phr}$ waste derived fillers. Composites in this group had the highest $300 \%$ modulus, the greatest hardness, the lowest elongation at break, and high tensile strength (more than $21 \mathrm{MPa}$ ). Overall properties of composites in this cluster are different from all the other clusters, and were distinct from carbon black, which fell in cluster 6 . However, mechanical properties of the composites in cluster 3 are more similar to composites in clusters 4, 5 or 6 than to clusters 1 or 2 (Fig. 7). Cluster 4 (Fig.8 second row, right) contains composites manufactured by partially replacing carbon black with 5 , 10 and $20 \mathrm{phr}$ of micro sized ES. This group of composites possesses relatively high 300\% modulus (greater than 2.3 MPa), medium hardness (hardness number 40 - 45), high elongation at break (greater than $1820 \%$ ), combined with the highest tensile strength of all the clusters.

Composites gathered in cluster 5 (Fig.8 third row, left) present a balance of all properties, with medium values of $300 \%$ modulus (1.7 - 2.3 MPa), medium hardness, medium elongation at break, and medium tensile strength (13 - $21 \mathrm{MPa}$ ). This cluster groups six of the composites made with $20 \mathrm{phr}$ of waste derived fillers. Finally, cluster 6 (Fig. 8 third row, right) groups the carbon black reference composite and most of the composites manufactured with $10 \mathrm{phr}$ of waste derived fillers. This group of composites had high 300\% modulus, high hardness (hardness number greater than 45), low elongation at break (less than $1550 \%$ ), and medium tensile strength. Based on the mechanical properties, cluster 6 is more similar to cluster 5 than to cluster 4 or 3 (Fig. 7).

\section{Discussion}

Waste-derived fillers, ES, TP, CFA and GB effectively reinforced GNR (Figs. 4 and 8), due to good polymer-filler interfacial adhesion, as reflected in the composite morphology (Fig. 5). However, this hypothesis is based on SEM evaluation of composites, and requires deeper analysis. Filler dispersion within the polymer also contributed to the good performance properties. Uniform 
dispersion of the particles and relative good interfacial interaction between the particles and the polymer allows efficient stress transfer, leading to improved tensile strength and resistance to deformation compared to unfilled vulcanized GNR. Composites made with micro waste-derived fillers, without carbon black, performed better than those made with macro sized particles (Fig. 4). This is unsurprising, because bigger particles have less surface area per unit weight than smaller particles, and so have less interaction with the polymer, and also can generate flaws within the composite material. Micro sized particles had a lower bulk density than macro sized particles. This is probably due to the broader particle size distribution of the macro sized particles, which allowed better packaging by fitting the smallest particles in between the spaces of the bigger particles.

Composites made with $5 \mathrm{phr}$ of waste-derived particles as co-fillers with $30 \mathrm{phr}$ carbon black, showed higher tensile strength and elongation to break compared to composites manufactured solely with carbon black. Interaction between these waste-derived filler particles, as well as interactions between the particles and the rubber, may be the cause of such reinforcement. The waste-derived fillers studied are more polar than carbon black but less polar than silica or commercial calcium carbonate due to their complex compositions. Therefore, hydrophobic components of the waste-derived fillers allow affinity to the rubber.

Filler-filler interactions existing between particles with polar surfaces, are mainly due to hydrogen bonding (Byers, 2001; Kato et al., 2014). This type of interaction is stronger than those of nonpolar fillers, such as carbon black, in which filler-filler interactions are due to van der Waals forces (Fröhlich et al., 2005). When filler volume reaches the percolation threshold, this strong fillerfiller interaction promotes the formation of a percolation network that contributes to the overall reinforcement of the material by restricting chain mobility. The linear chain structure of GNR allows it to flow more easily into the filler network than HNR, which has a branched structure (Rensch et al., 1986). Thus, when stress is applied to the materials, entanglement of polymer chains in this filler network allows better load transfer between the filler and the polymer than in HNR (Barrera and Cornish, 2015).

The percolation threshold is dependent on the aspect ratio (length to diameter ratio) of the filler and the degree of dispersion (Bandyopadhyay-Ghosh et al., 2015; Peddini et al., 2014), and varies among the different fillers used. Rod shaped particles, such as GB (Fig. 2f), have a higher aspect 
ratio than the other fillers (Fig. 2). Uniformly dispersed fillers with high aspect ratio require lower volumes of material to form the percolation network (Angellier et al., 2005; BandyopadhyayGhosh et al., 2015). GB also had the lowest bulk density among the waste derived fillers (Table 2), and so had larger volumes of particles in composites with similar weight loadings. As the volume of filler increases beyond the percolation threshold, interfacial interaction between filler particles are favored over polymer-filler interactions. Filler-filler interactions are less effective than polymer-filler interactions at supporting stress transfer through the material and hence a lower tensile strength was achieved at high loadings of GB compared to the other waste-derived fillers (Fig.4).

Hybrid carbon black/waste-derived filler/GNR composites made with $10 \mathrm{phr}$ of waste-derived particles had similar properties to those of composites manufactured solely with carbon black. At low loadings of waste-derived fillers ( $5 \mathrm{phr}$ ), carbon black predominates the reinforcement of the material, and the waste-derived fillers further enhanced the reinforcement. Carbon black not only has a good interfacial interaction with the polymer, but also the smallest particle size (108 $\mathrm{nm})$. Small particle sizes together with high loading (30 phr of carbon black and only 5 phr of wastederived filler in the composites), generate a larger interfacial contact area for polymer-filler interaction and good reinforcement. However, as the amount of carbon black decreased below 30 phr the overall reinforcement was also decreased.

Composites made with high loading (20 and $35 \mathrm{phr}$ ) of most of the waste-derived fillers, had lower values of tensile strength and 300\% modulus than carbon black composites (Fig. 3), reflecting a lower reinforcing effect of the non-carbon black fillers. Despite the relative good polymer-filler interaction observed between GNR and the waste derived-fillers (Fig. 5), and the contribution of the filler network to the reinforcement of the materials, these interactions are not as strong as the interaction of the polymer with carbon black. By increasing the waste-derived filler and reducing the carbon black fraction, the interfacial interaction between the matrix and non-carbon black filler may fail, creating voids in the composite. These voids concentrate the stress and result in composite fracture.

Strong interfacial interaction between GNR and carbon black was also reflected by the swelling of the composites. Composites containing low loadings (5phr) of waste derived filler and those 
containing only carbon black had the lowest swelling and the highest crosslink density (Table 3). Rubber-filler interaction is dependent on the surface activity of the filler. Carbon black possesses a relative non-polar surface (Byers, 2001), which is more compatible with natural rubber than more polar fillers. The strong carbon black-rubber interaction is mainly physical in nature (van der Waals forces) (Fröhlich et al., 2005). These weak interfacial forces allow carbon black to behave as an additional crosslinker in the NR network (Chenal et al., 2007) by restricting chain mobility and generating stronger and harder materials.

Composites made solely with TP and ES had higher crosslink density than composites made with GB or CFA (Table 3) and unfilled compound. Solvent absorption measurements yield an apparent crosslink density that can be explained by sum of both chemical crosslinks and physical crosslink, such as entanglement of polymer chain within the filler network (Lee et al., 1994). Higher crosslink density leads to the better mechanical properties, particularly modulus and tensile strength, attained by TP and ES /GNR composites.

Particle structure played an important role in the performance of the different composites. The micro sized TP structure (Fig. 2a) is similar to carbon black (Fig. 2b). This complex aggregate structure, along with the small particle size, allows the material to provide better reinforcement due to high degree of irregularity of the filler that limits the mobility of polymer chain under strain (Fröhlich et al., 2005), leading to increased stress at equivalent strain. This behavior is not observed in macro sized TP particles because, at this larger scale, the material has a laminar shape (Fig. 2c) and less surface area.

Although distinctly different from carbon black and micro sized TP, the ES and CFA particle structures provide high surface area due to roughness and porosity of the materials (Fig. 2d and 2e). ES porosity is the consequence of naturally occurring gas exchange pores (Intharapat et al., 2013) in eggshells which allow oxygen to pass from the atmosphere to the developing chick embryo. High surface area allows large contact interface between the polymer and the filler creating good interfacial adhesion.

Despite similarity in particle morphology, better performance properties were achieved by ES composites compared to CFA composites probably due to differences in their chemical composition. CFA is mainly composed of alumino-silicate (>50\%) (Kutchko and Kim, 2006). 
Silanol groups can react with rubber compounding ingredients, and can lead to slower curing (Byers, 2001). ES on the other hand, is over 95\% calcium carbonate (Intharapat et al., 2013), which can contributes to faster curing rates than silicate fillers due to alkalinity of the material (Byers, 2001). Given that processing conditions for all the composites were the same, slower curing rate may lead to lower crosslink density (Table 3), which translates into lower performance properties.

Increase in 300\% modulus and/or tensile strength often leads to a decrease in elongation at break (Angellier et al., 2005; Gerspacher and Wampler, 2001); however, this was not the case for the waste-derived fillers (Fig. 4). This confirms that the interfacial interaction is not the result of chemical bonding such as those achieved by coupling agents. Under strain, the adhesion forces can break and relocate allowing the polymer chains to rearrange while effectively transferring stress. This characteristic generated materials which maintained flexibility while also exhibiting resistance to deformation.

The reinforcement of GNR with waste-derived fillers as co-fillers with carbon black, offer the potential to engineer materials with a varied combination of properties (Fig. 8). These combinations result from the modification of waste-derived filler/carbon black ratio in the composite, as well as the type of waste-derived filler and its particle size. Consequently, these fillers can be added not only to reduce cost, but to target specific performance requirements for elastomeric products. Potential applications for composites in cluster 1 and 2 include rubber bands, insulating rubber tapes and any other rubber products that require really flexible materials with medium to low values of tensile strength, hardness and $300 \%$ modulus. Composites in these two clusters surpass requirements for tensile strength and elongation at break specified in ASTM D4388 (ASTM International, 2013c) for insulating rubber tapes. Flexible composites made with lightweight materials such as GB, can also be good candidates for sponges and expanded rubber products.

Composites in cluster 3 possess high tensile strength, 300\% modulus and hardness, making these composites good candidates for more demanding applications such as tire components. Potential uses for composites in cluster 4 include rubber surgical drainage tubes, due to the combination of high elongation, high modulus and tensile strength exhibited by these composites. These composites exceed requirements for tensile strength and elongation at break specified in ASTM 
D3579 (ASTM International, 2010b) for rubber surgical drainage tube, penrose type. Insulating materials, namely insulating line hose, blankets, sleeves and gloves are some of the potential usage of composites grouped in Cluster 5. Composites in cluster 6 exceed tensile strength, elongation at break and hardness requirements for elastomeric seals for joining concrete structures as specified in ASTM C1619 (ASTM International, 2011).

Partial replacement of carbon black with waste-derived fillers in GNR composites enhanced overall reinforcement, leading to stronger composites than those made solely with carbon black. This outstanding reinforcement was not attained for HNR composites made with the same wastederived fillers in a previous study (Barrera and Cornish, 2015), due to differences in rubber structure and composition (non-rubber components). The macromolecular structure of HNR is branched (Tanaka, 2001), making it bulkier than the linear GNR, and this may impede the polymer filler network which can be established especially with the porous fillers. Non-rubber components, such as proteins and phospholipids are involved in the branched structure of HNR, by serving as reactive groups for the formation of branch-points (Sakdapipanich et al., 1999). The marked differences between the interactions of the two NRs with the fillers is most evident for the TPderived fillers: GNR composites containing $35 \mathrm{phr}$ of micro sized TP had the highest tensile strength (18.7 $\pm 0.47 \mathrm{MPa})$ among the $35 \mathrm{phr}$ waste-derived composites. Moreover, tensile strength of GNR composites made with $20 \mathrm{phr}$ of micro sized TP and $15 \mathrm{phr}$ of carbon black, was not significantly different from the tensile strength of composites containing carbon black alone. However, in HNR, $35 \mathrm{phr}$ and $20 \mathrm{phr}$ of micro-sized TP could not even be mixed in to generate a cohesive composite (Barrera and Cornish, 2015).

Waste-derived materials have a lower carbon footprint than petroleum-derived materials such as carbon black. Additionally, reductions in carbon black production capacity in North America are expected by 2020 (Rubber and Plastic News, 2014) due to increasing regulation by the U.S. Environmental Protection Agency (EPA) because of different pollutants, namely sulfur dioxide, nitrogen oxide and particulate matter, generated during its manufacture. Reinforcement of GNR by partially or completely replacing carbon black with these micro sized fillers, can improve the sustainability of rubber industry and mitigate potential carbon black shortfalls in the future. Solid wastes such as ES and TP are continuously generated in large volumes. In 2012, 12 million tons of processing tomatoes were harvested in the United States (Thornsbury et al., 2013) generating a 
processing waste of 437,574 metric tons of skins, while 95.176 billion eggs were produced in the United States 2013 (United States Department of Agriculture, 2014) generating 596,754 metrics tons of shells. Economics of GNR production and other industries also could be improved by the use of these waste-derived fillers, which not only can be cheaply made but also entail significant savings for cost associated to disposal of these residues.

It is particularly interesting that low loadings of micro sized waste-derived fillers, especially ES as co-filler with nano-carbon black, performed as well as the nano-carbon black alone. The use of nano sized waste-derived fillers could potentially result in better properties than those achieved with micro sized filler. However, nano fillers are much more difficult and expensive to manufacture at large scale than micro-fillers. Unique properties of GNR, such as malleability at extreme cold temperatures (Cornish and Wood, 2002), along with the high performance achieved by the addition of waster-derived fillers, offer the possibility to use this rubber for value-added products and markets that are not possible even for HNR.

\section{Conclusion}

Waste-derived fillers can improve guayule rubber performance while reducing the amount of petroleum-derived carbon black in the final product. Flexible materials with comparable tensile strength to $100 \%$ carbon black composites were achieved by low loading of micro sized wastederived fillers, particularly those made from eggshells and tomato peels as co-filler with carbon black. This is important considering the renewable character of these materials, and possible applications for these composites in which these new combination of mechanical properties can be exploited. Moreover, remarkable improvement of tensile strength and elongation at break beyond those achieved by carbon black alone was achieved by micro sized eggshell composites up to $20 \mathrm{phr}$ of eggshell and only $15 \mathrm{phr}$ of carbon black. Thus, eggshells are a promising reinforcing filler for the manufacturing of high performance rubber products. The superior reinforcement obtained may reflect a synergistic reinforcing effect of carbon black particles with the formation of a unique network between the guayule rubber and the waste-derived materials, not attainable with Hevea brasiliensis natural rubber. Moreover, hybrid carbon black/wastederived filler/guayule composites presented crosslink densities similar to that of carbon black. This 
is consistent with crosslink density being an extremely important factor controlling the physical properties of vulcanized rubber. Partial replacement of carbon black with these cheaply made particles could alleviate future carbon black shortages.

\section{Acknowledgments}

We thank Ohio Third Frontier, Ohio Research Scholars Program in Technology-Enabling and Emergent Materials (TECH 09-026), Institute for Materials Research Facility Grant, The Ohio State University and USDA National Institute of Food and Agriculture (Hatch project 230837) for providing financial support for this project. We also thank the Fulbright Foundation for sponsoring Cindy Barrera during her PhD. Program.

\section{Reference}

Ahmadi, M., Shojaei, A., 2013. Cure kinetic and network structure of NR/SBR composites reinforced by multiwalled carbon nanotube and carbon blacks. Thermochim. Acta 566, 238248. doi:10.1016/j.tca.2013.06.004

Angellier, H., Molina-Boisseau, S., Dufresne, A., 2005. Mechanical properties of waxy maize starch nanocrystal reinforced natural rubber. Macromolecules 38, 9161-9170. doi:10.1021/ma0512399

ASTM International, 2013a. ASTM standard D412 - 06a. Standard test methods for vulcanized rubber and thermoplastic elastomers- tension. doi:10.1520/D0412-06AR13

ASTM International, 2013b. ASTM standard D6814 - 02. Standard Test Method for Determination of Percent Devulcanization of Crumb Rubber Based on Crosslink Density. doi:10.1520/D6814-02R13

ASTM International, 2013c. ASTM D4388-13. Standard Specification for Nonmetallic SemiConducting and Electrically Insulating Rubber Tapes. doi:10.1520/D4388-13

ASTM International, 2011. ASTM C1619-11 Standard Specification for Elastomeric Seals for 
Joining Concrete Structures. doi:10.1520/C1619-11

ASTM International, 2010a. ASTM standard D2240-05. Standard Test Method for Rubber Property—Durometer Hardness. doi:10.1520/D2240-05R10

ASTM International, 2010b. ASTM D3579-77. Standard Specification for Rubber Surgical Drainage Tubes, Penrose-Type. doi:10.1520/D3579-77R10

Bandyopadhyay-Ghosh, S., Ghosh, S.B., Sain, M., 2015. The use of biobased nanofibres in composites, in: Faruk, O., Sain, M. (Eds.), Biofiber Reinforcements in Composite Materials. Woodhead Publishing Limited, Sawston, Cambridge, pp. 571-647. doi:10.1533/9781782421276.5.571

Barrera, C.S., Cornish, K., 2015. Novel Mineral and Organic Materials from Agro-Industrial Residues as Fillers for Natural Rubber. J. Polym. Environ. 23, 437-448. doi:10.1007/s10924015-0737-4

Bras, J., Hassan, M.L., Bruzesse, C., Hassan, E. a., El-Wakil, N. a., Dufresne, A., 2010. Mechanical, barrier, and biodegradability properties of bagasse cellulose whiskers reinforced natural rubber nanocomposites. Ind. Crops Prod. 32, 627-633. doi:10.1016/j.indcrop.2010.07.018

Byers, J.T., 2001. Filler- Non-black, in: Baranwal, K.C., Stephens, H.L. (Eds.), Basic Elastomer Technology. American Chemical society, Rubber division, Akron, Ohio, pp. 82-111.

Carey, A.B., Cornish, K., Schrank, P., Ward, B., Simon, R., 1995. Cross-reactivity of alternate plant sources of latex in subjects with systemic IgE-mediated sensitivity to Hevea brasiliensis latex. Ann. allergy, asthma Immunol. 74, 317-320.

Castillo, J.E., Hernandez, R.M., Campos-Lopez, E., 1979. Specific heats of guayule and natural rubbers above the glass transition temperature. Thermochim. Acta 33, 323-329.

Chenal, J.M., Gauthier, C., Chazeau, L., Guy, L., Bomal, Y., 2007. Parameters governing strain induced crystallization in filled natural rubber. Polymer (Guildf). 48, 6893-6901. doi:10.1016/j.polymer.2007.09.023

Choi, I.S., Roland, C.M., 1997. Strain-Crystallization of Guayule and Hevea Rubbers. Rubber Chem. Technol. 70, 202-210. doi:10.5254/1.3538425 
Cornish, K., 2001. Similarities and differences in rubber biochemistry among plant species. Phytochemistry 57, 1123-1134. doi:10.1016/S0031-9422(01)00097-8

Cornish, K., 1996. Hypoallergenic natural rubber products from parthenum argentatum (gray) and other non-hevea brasiliensis species. U.S. Patent, No. 5,580,942.

Cornish, K., Wood, D.F., 2002. Visualization of the malleability of the rubber core of rubber particles from Parthenium argentatum Gray and other rubber-producing species under extremely cold temperatures. J. Polym. Environ. 10, 155-162. doi:10.1023/A:1021196121296

Donnet, J.B., 2003. Nano and microcomposites of polymers elastomers and their reinforcement. Compos. Sci. Technol. 63, 1085-1088. doi:10.1016/S0266-3538(03)00028-9

Fröhlich, J., Niedermeier, W., Luginsland, H.D., 2005. The effect of filler-filler and fillerelastomer interaction on rubber reinforcement. Compos. Part A Appl. Sci. Manuf. 36, 449460. doi:10.1016/j.compositesa.2004.10.004

Gerspacher, M., Wampler, W., 2001. Fillers - Carbon black, in: Baranwal, K.C., Stephens, H.. (Eds.), Basic Elastomer Technology. America Chemical Society, Rubber Division, Akron, Ohio, pp. 57-81.

Gopalan Nair, K., Dufresne, A., 2003. Crab shell chitin whisker reinforced natural rubber nanocomposites. 1. Processing and swelling behavior. Biomacromolecules 4, 657-665. doi:10.1021/bm020127b

Hamilton, R.G., Cornish, K., 2010. Immunogenicity studies of guayule and guayule latex in occupationally exposed workers. Ind. Crops Prod. 31, 197-201. doi:10.1016/j.indcrop.2009.09.012

International Rubber Study Group IRSG, 2015. Rubber Statistical Bulletin, Quarterly statistics. Statistical summary of world rubber situation [WWW Document]. URL http://www.rubberstudy.com/documents/WebSiteData_Aug2015.pdf

International Rubber Study Group IRSG, 2014. The world rubber industry outlook- Review and Prospects to 2023 [WWW Document]. URL http://www.rubberstudy.com

Intharapat, P., Kongnoo, A., Kateungngan, K., 2013. The Potential of Chicken Eggshell Waste as 
a Bio-filler Filled Epoxidized Natural Rubber (ENR) Composite and its Properties. J. Polym. Environ. 21, 245-258. doi:10.1007/s10924-012-0475-9

Kato, a., Kokubo, Y., Tsushi, R., Ikeda, Y., 2014. Hydrophobic and hydrophilic silica-filled crosslinked natural rubber (NR): structure and properties, in: Kohjiya, S., Ikeda, Y. (Eds.), Chemistry, Manufacture and Applications of Natural Rubber. Woodhead Publishing Limited, Sawston, Cambridge, pp. 193-215. doi:10.1533/9780857096913.1.193

Kohls, D.J., Beaucage, G., 2002. Rational design of reinforced rubber. Curr. Opin. Solid State Mater. Sci. 6, 183-194. doi:10.1016/S1359-0286(02)00073-6

Kutchko, B.G., Kim, A.G., 2006. Fly ash characterization by SEM-EDS. Fuel 85, 2537-2544. doi:10.1016/j.fuel.2006.05.016

Leblanc, J.L., 2002. Rubber-filler interactions and rheological properties in filled compounds. Prog. Polym. Sci. 27, 627-687. doi:10.1016/S0079-6700(01)00040-5

Lee, S., Pawlowski, H., Coran, A.Y., 1994. Method for Estimating the Chemical Crosslink Densities of Cured Natural Rubber and Styrene-Butadiene Rubber. Rubber Chem. Technol. 67, 854-864. doi:10.5254/1.3538716

McMahan, C., Kostyal, D., Lhamo, D., Cornish, K., 2015. Protein influences on guayule and Hevea natural rubber sol and gel. J. Appl. Polym. Sci. 42051, n/a-n/a. doi:10.1002/app.42051

Pasquini, D., Teixeira, E.D.M., Curvelo, A.A.D.S., Belgacem, M.N., Dufresne, A., 2010. Extraction of cellulose whiskers from cassava bagasse and their applications as reinforcing agent in natural rubber. Ind. Crops Prod. 32, 486-490. doi:10.1016/j.indcrop.2010.06.022

Peddini, S.K., Bosnyak, C.P., Henderson, N.M., Ellison, C.J., Paul, D.R., 2014. Nanocomposites from styrene-butadiene rubber (SBR) and multiwall carbon nanotubes (MWCNT) part 1: Morphology and rheology. Polym. (United Kingdom) 55, 258-270. doi:10.1016/j.polymer.2013.11.003

Ponciano, G., McMahan, C.M., Xie, W., Lazo, G.R., Coffelt, T. a., Collins-Silva, J., Nural-Taban, A., Gollery, M., Shintani, D.K., Whalen, M.C., 2012. Transcriptome and gene expression analysis in cold-acclimated guayule (Parthenium argentatum) rubber-producing tissue. Phytochemistry 79, 57-66. doi:10.1016/j.phytochem.2012.04.007 
Porter, L.S., Stephens, H.L., 1979. Effects of compounding variations on the properties of guayule rubber. Rubber Chem. Technol. 52, 361- 376.

Ramos-De Valle, L.F., Ramirez, R.R., 1982. Thermoplastic-guayule rubber blends-composition and mechanical properties. Rubber Chem. Technol. 55, 1328- 1340.

Rasutis, D., Soratana, K., Mcmahan, C., Landis, A.E., 2015. A sustainability review of domestic rubber from the guayule plant. Ind. Crop. Prod. 70, 383-394. doi:10.1016/j.indcrop.2015.03.042

Ray, D.T., Coffelt, T. a., Dierig, D. a., 2005. Breeding guayule for commercial production. Ind. Crops Prod. 22, 15-25. doi:10.1016/j.indcrop.2004.06.005

Ray, D.T., Foster, M.A., Coffelt, T.A., McMaham, C., 2010. Guayule: Culture, Breeding and Rubber Production, in: Singh, B.P. (Ed.), Industrial Crops and Uses. CABI Publishing, Wallingford, Oxon, pp. 384- 410. doi:10.1079/9781845936167.0384

Rensch, G.J., Phillips, P.J., Vatansever, N., Gonzalez, V. a., 1986. The Crystallization Behavior of Cis-polyisoprenes Extracted from the Guayule Plant. J. Polym. Sci. Part B Polym. Phys. 24, 1943. doi:10.1002/polb.1986.090240904

Rubber and Plastic News, 2014. King: U.S. tire industry may face carbon black shortage.

Sakdapipanich, J.T., Kowitteerawut, T., Suchiva, K., Tanaka, Y., 1999. Long-Chain Branching and Mechanism Controlling Molecular Weight in Hevea Rubber. Rubber Chem. Technol. 72, 712-720.

Schloman, W.W., 2005. Processing guayule for latex and bulk rubber. Ind. Crops Prod. 22, 4147. doi:10.1016/j.indcrop.2004.04.031

Sheehan, C.., Bisio, A.L., 1966. Polymer/Solvent Interaction Parameters. Rubber Chem. Technol. 39, 149-192. doi:10.5254/1.3544827

Siler, D.J., Cornish, K., 1995. Measurement of Protein in Natural Rubber Latex.pdf. Anal. Biochem. 229, 278-281.

Siler, D.J., Cornish, K., 1994. Hypoallergenicity of guayule rubber particle proteins compared to Hevea latex proteins. Ind. Crops Prod. 2, 307-313. doi:10.1016/0926-6690(94)90122-8

Siler, D.J., Cornish, K., Hamilton, R.G., 1996. Absence of cross-reactivity of IgE antibodies from 
subjects allergic to Hevea brasiliensis latex with a new source of natural rubber latex from guayule (Parthenium argentatum). J. Allergy Clin. Immunol. 98, 895-902. doi:Doi 10.1016/S0091-6749(96)80005-4

Steinbüchel, A., 2003. Production of rubber-like polymers by microorganisms. Curr. Opin. Microbiol. 6, 261-270. doi:10.1016/S1369-5274(03)00061-4

Tanaka, Y., 2001. Structural Characterization of Natural Polyisoprenes: Solve the Mystery of Natural Rubber Based on Structural Study. Rubber Chem. Technol. 74, 355-375. doi: $10.5254 / 1.3547643$

Thornsbury, S., Wells, H.F., Bond, J., 2013. Vegetables and Pulses Yearbook Data.

United States Department of Agriculture, 2014. Chickens and Eggs 2013 Summary. National Agricultural Statistics Service.

van Beilen, J.B., Poirier, Y., 2007. Establishment of new crops for the production of natural rubber. Trends Biotechnol. 25, 522-529. doi:10.1016/j.tibtech.2007.08.009

Visakh, P.M., Thomas, S., Oksman, K., Mathew, A.P., 2012. Crosslinked natural rubber nanocomposites reinforced with cellulose whiskers isolated from bamboo waste: Processing and mechanical/thermal properties. Compos. Part A Appl. Sci. Manuf. 43, 735-741. doi:10.1016/j.compositesa.2011.12.015.

\section{Figures caption}

Fig. 1: Macro _ _ and micro _ _ _ sized fillers' particle size distribution. a) Carbon fly ash; macro (median: $76.20 \mu \mathrm{m}$, mean: $89.32 \mu \mathrm{m}$, SD: $61.94 \mu \mathrm{m}$ ), micro (median: $11.25 \mu \mathrm{m}$, mean: $12.12 \mu \mathrm{m}$, SD: $4.93 \mu \mathrm{m}$ ), b) eggshells; macro (median: $230.33 \mu \mathrm{m}$, mean: $241.46 \mu \mathrm{m}$, SD: $111.01 \mu \mathrm{m}$ ), micro (median: $16.07 \mu \mathrm{m}$, mean: $23.19 \mu \mathrm{m}$, SD: $20.79 \mu \mathrm{m}$ ), c) guayule bagasse; macro (median: 243.10 $\mu \mathrm{m}$, mean: $279.33 \mu \mathrm{m}$, SD: $188.56 \mu \mathrm{m}$ ), micro (median: $49.09 \mu \mathrm{m}$, mean: $54.75 \mu \mathrm{m}$, SD: 30.63 $\mu \mathrm{m}$ ), d) tomato peels; macro (median: $170.70 \mu \mathrm{m}$, mean: $179.02 \mu \mathrm{m}$, SD: $154.91 \mu \mathrm{m}$ ), micro (median: $23.08 \mu \mathrm{m}$, mean: $26.95 \mu \mathrm{m}$, SD: $17.00 \mu \mathrm{m}$ ) 
Fig. 2: SEM micrographs of filler particles. (a) Micro sized processing tomato peels; (b) carbon black; (c) macro sized processing tomato peels, (d) Micro sized carbon fly ash; (e) Micro sized eggshells; (f) Micro sized guayule bagasse.

Fig. 3: Mechanical properties of guayule rubber composites manufactured using micro ........ and macro __ sized particles obtained from different waste-derived materials. Total amount of filler (carbon black plus waste-derived filler), in all samples was $35 \mathrm{phr}$. As the waste filler loading increases the carbon black filler decreases by the same weight amount as represented by the double $\mathrm{X}$ axis.

Fig. 4: Mechanical properties of guayule rubber composites containing $35 \mathrm{phr}$ of each individual filler.

Fig. 5:SEM micrograph of guayule rubber composites with a) carbon fly ash, micro, 35 phr; b) eggshells, micro, $35 \mathrm{phr}$; c) guayule bagasse, micro, $35 \mathrm{phr}$; d) processing tomato peels, micro, 35 phr.

Fig. 6: Guayule rubber composites swelling behavior. Unfilled -0 , carbon black $-\bullet$, carbon fly ash $5 \mathrm{phr} \_$, carbon fly ash $35 \mathrm{phr} \triangle$, eggshells $5 \mathrm{phr} \_$, eggshells $35 \mathrm{phr}$-.--.--., guayule bagasse $5 \mathrm{phr} \smile$, guayule bagasse $35 \mathrm{phr} \diamond$, processing tomato peels $5 \mathrm{phr}-$, processing tomato peels $35 \mathrm{phr} \square$. (a) composites containing micro particles and (b) composites containing macro particles.

Fig. 7: Dendrogram obtained from hierarchical cluster analysis of 34 formulations. Composite labels represent the amount of waste-derived filler in the sample, filler type and particle size. Total amount of filler (carbon black plus waste-derived filler), in all samples was 35 phr. Filler type: carbon fly ash (CFA), guayule bagasse (GB), eggshells (ES), processing tomato peels (TP).

Fig. 8: Radar chart representing mechanical properties of composites in each of the cluster obtained from hierarchical cluster analysis of 34 formulations. Composite labels represent the amount of waste-derived filler in the sample, filler type and particle size. Total amount of filler (carbon black plus waste-derived filler), in all samples was 35 phr. Filler type: carbon fly ash (CFA), guayule bagasse (GB), eggshells (ES), processing tomato peels (TP). 
Fig. 1: Macro and micro sized fillers' particle size distributio
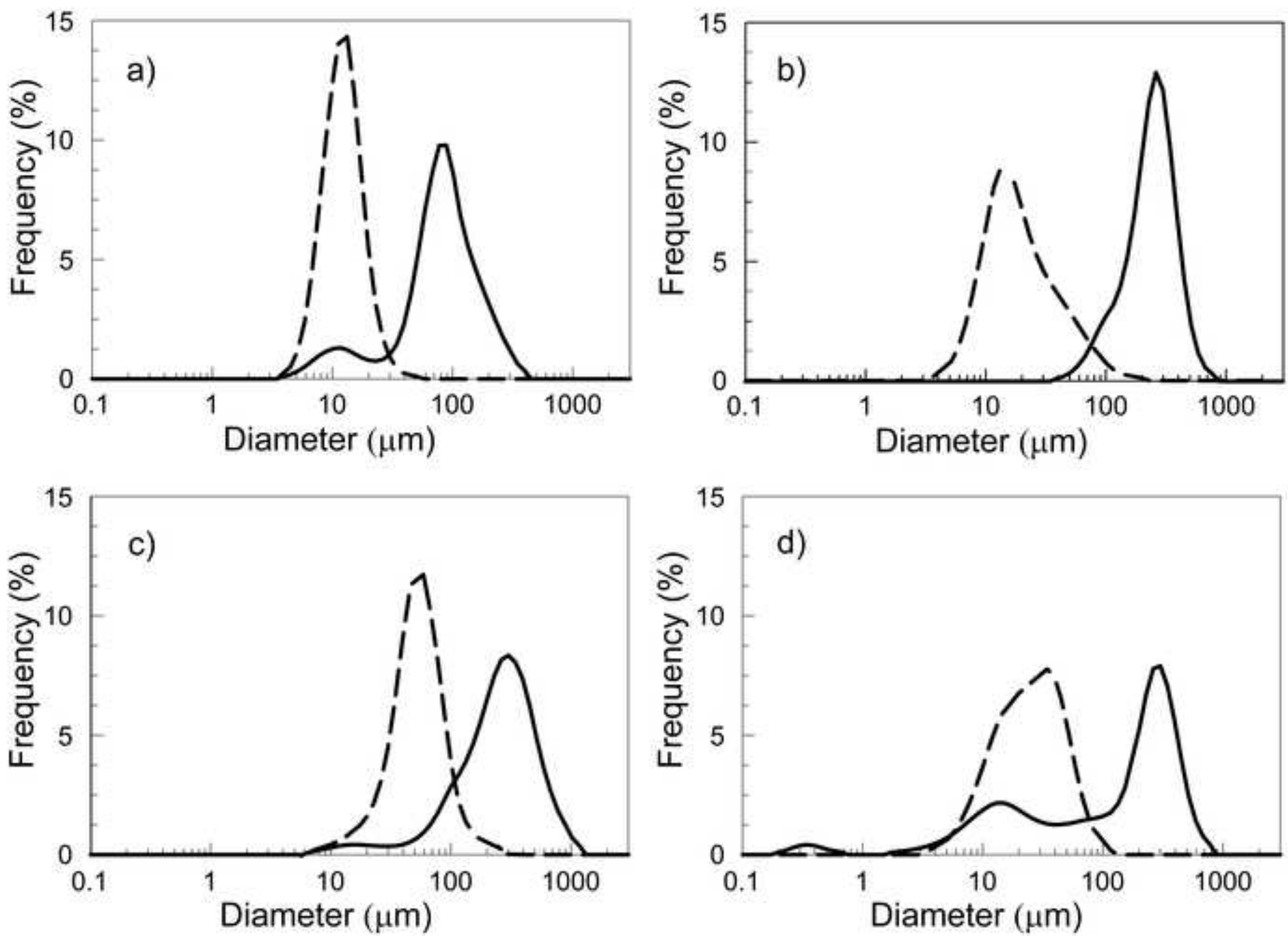


\section{a)}
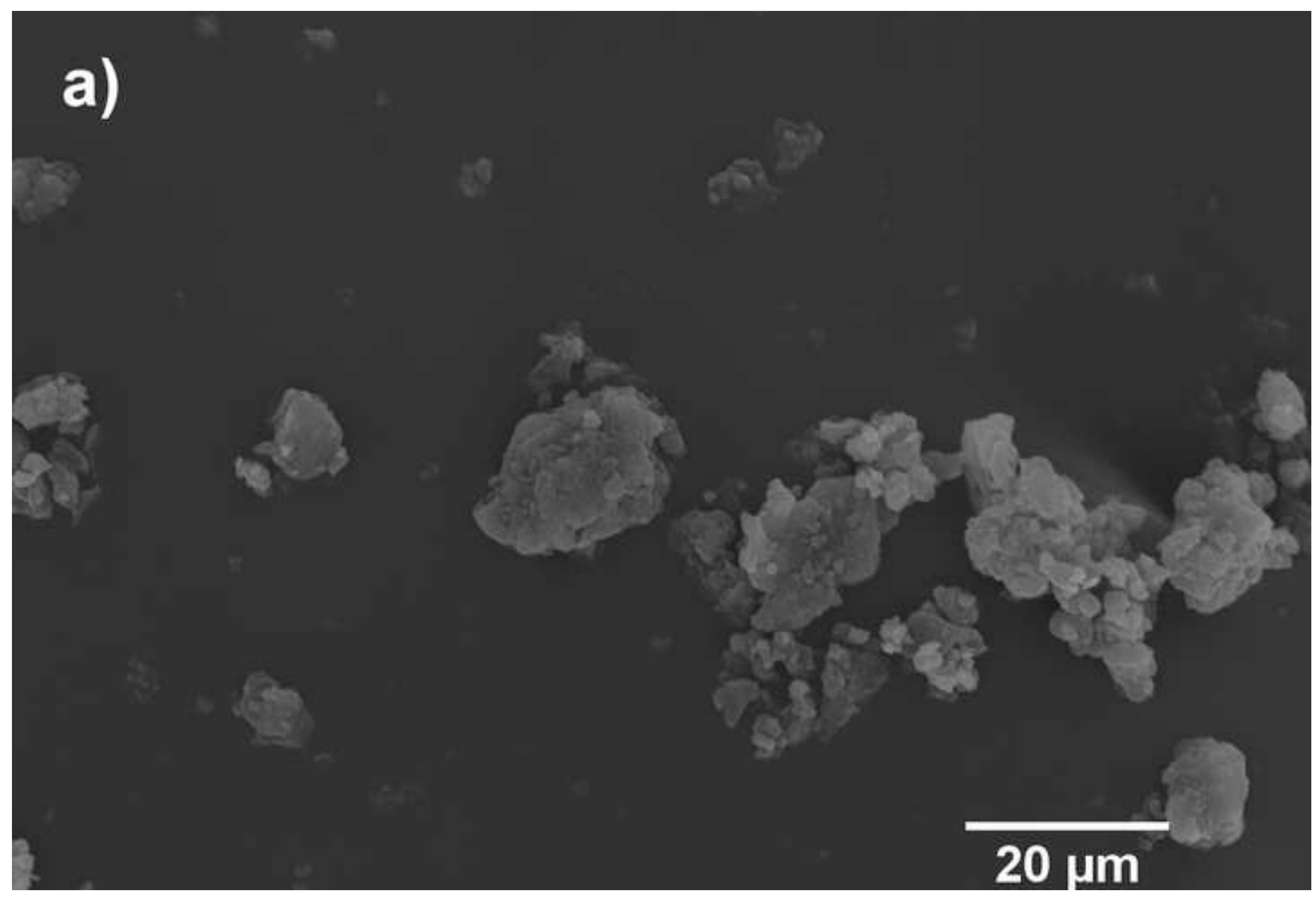

Fig. 2: SEM micrographs of filler particles. 


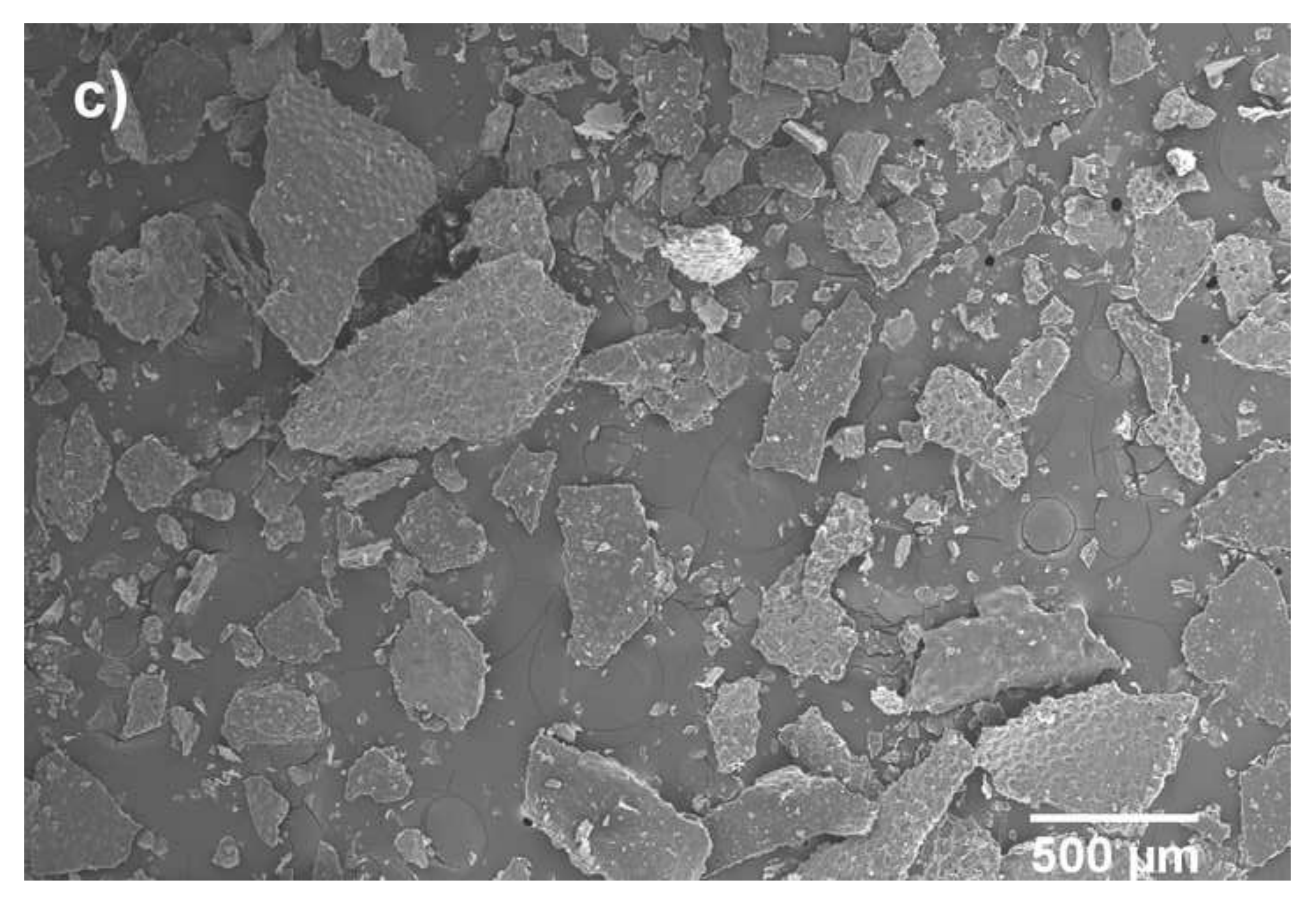

Fig. 2: SEM micrographs of filler particles

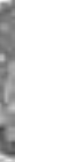

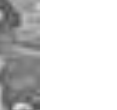

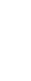
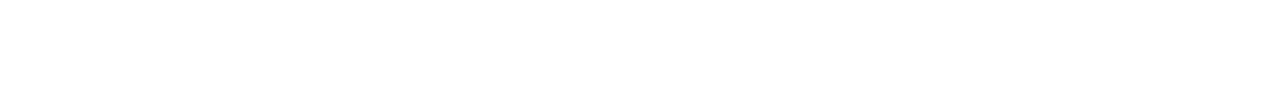
f)

\section{0 um}
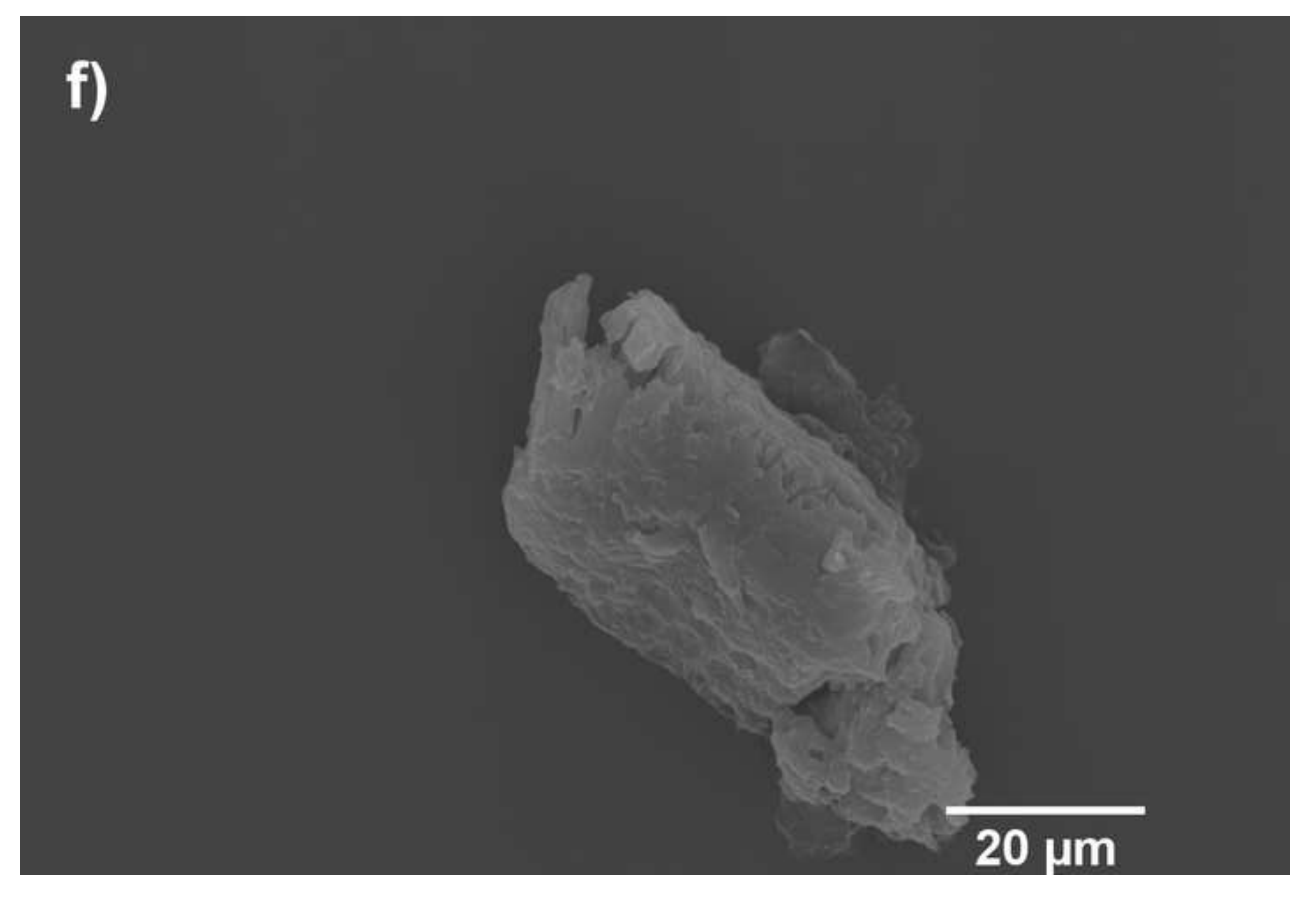

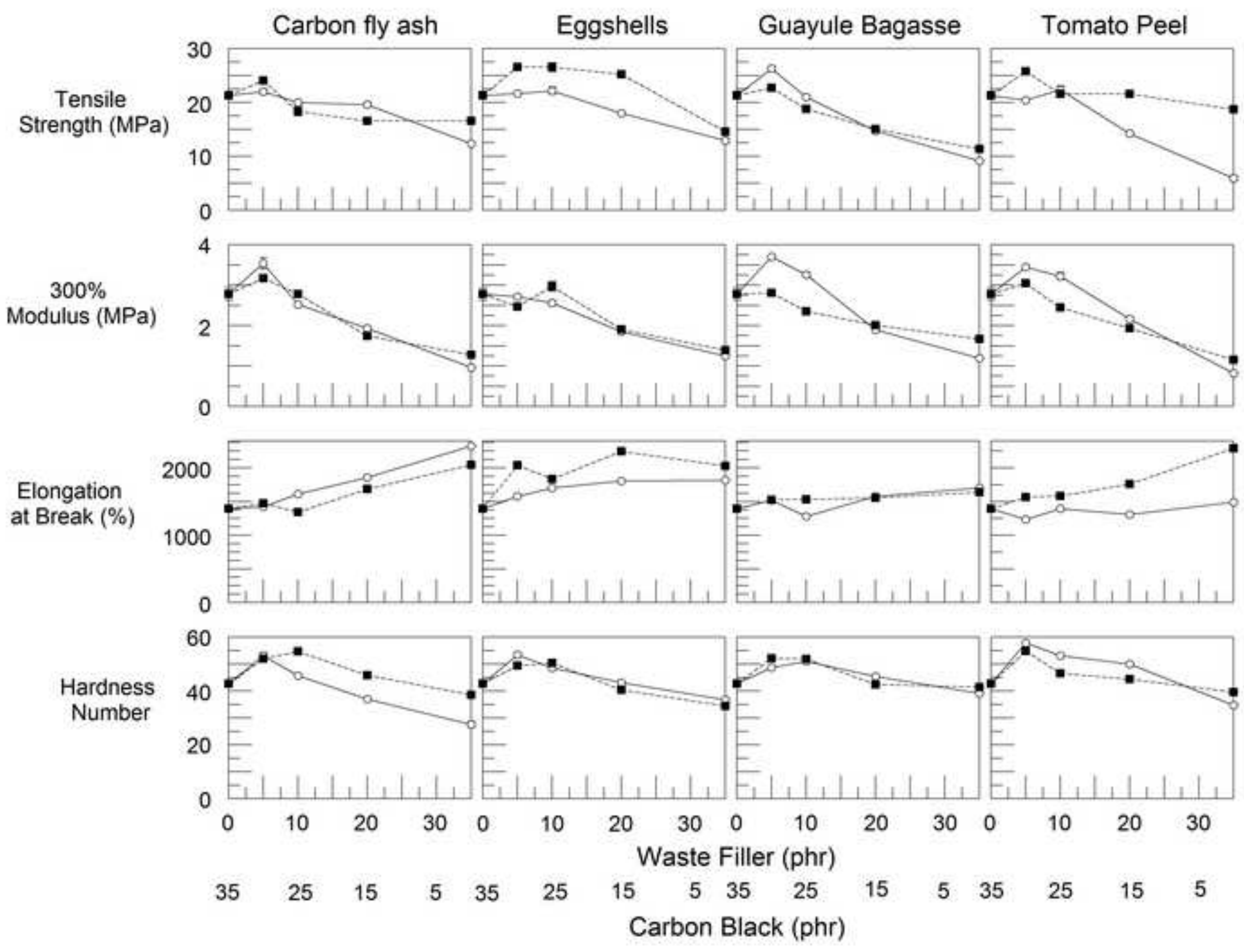
Tomato peels micro Tomato peels macro Carbon fly ash micro Carbon fly ash macro ¿ Bagasse micro 플 Bagasse macro Eggshells micro Eggshells macro Carbon black Unfilled

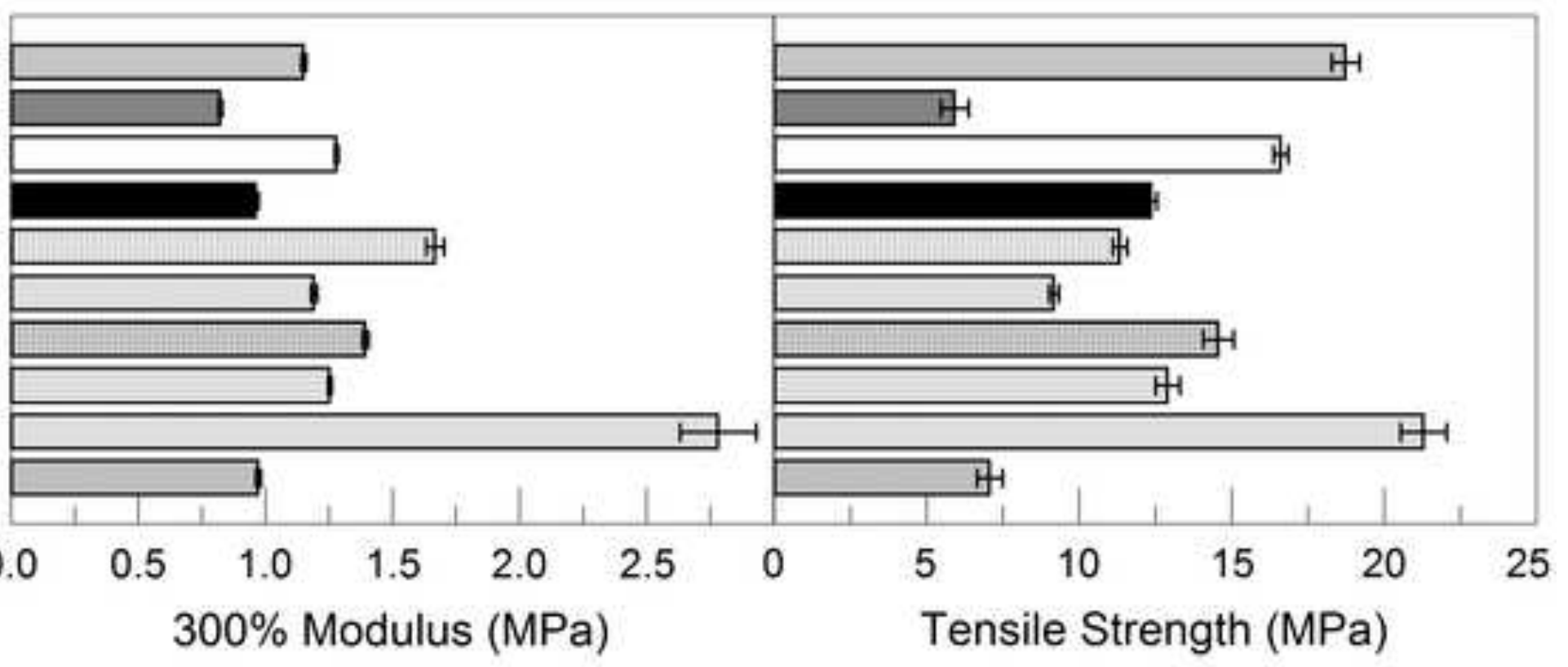

Tomato peels micro Tomato peels macro Carbon fly ash micro Carbon fly ash macro 高

Bagasse micro Bagasse macro Eggshells micro Eggshells macro Carbon black Unfilled

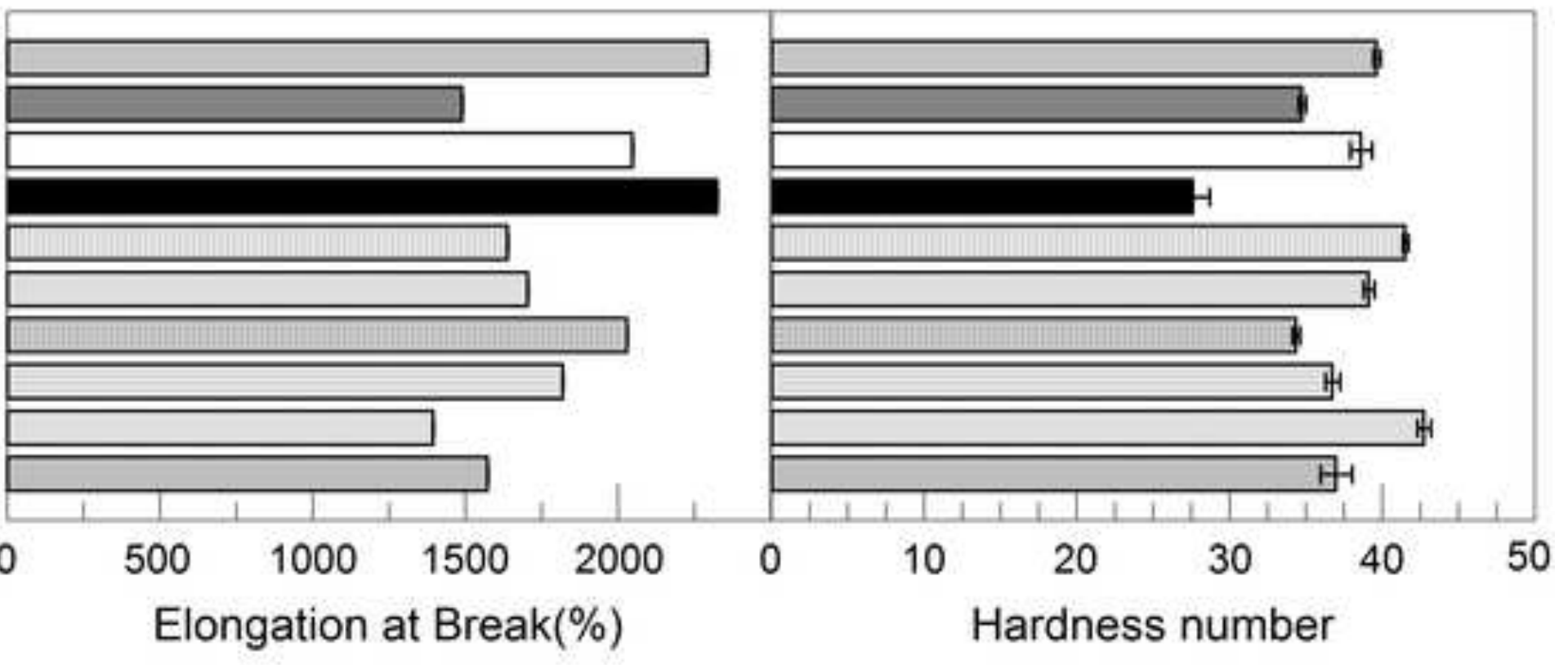




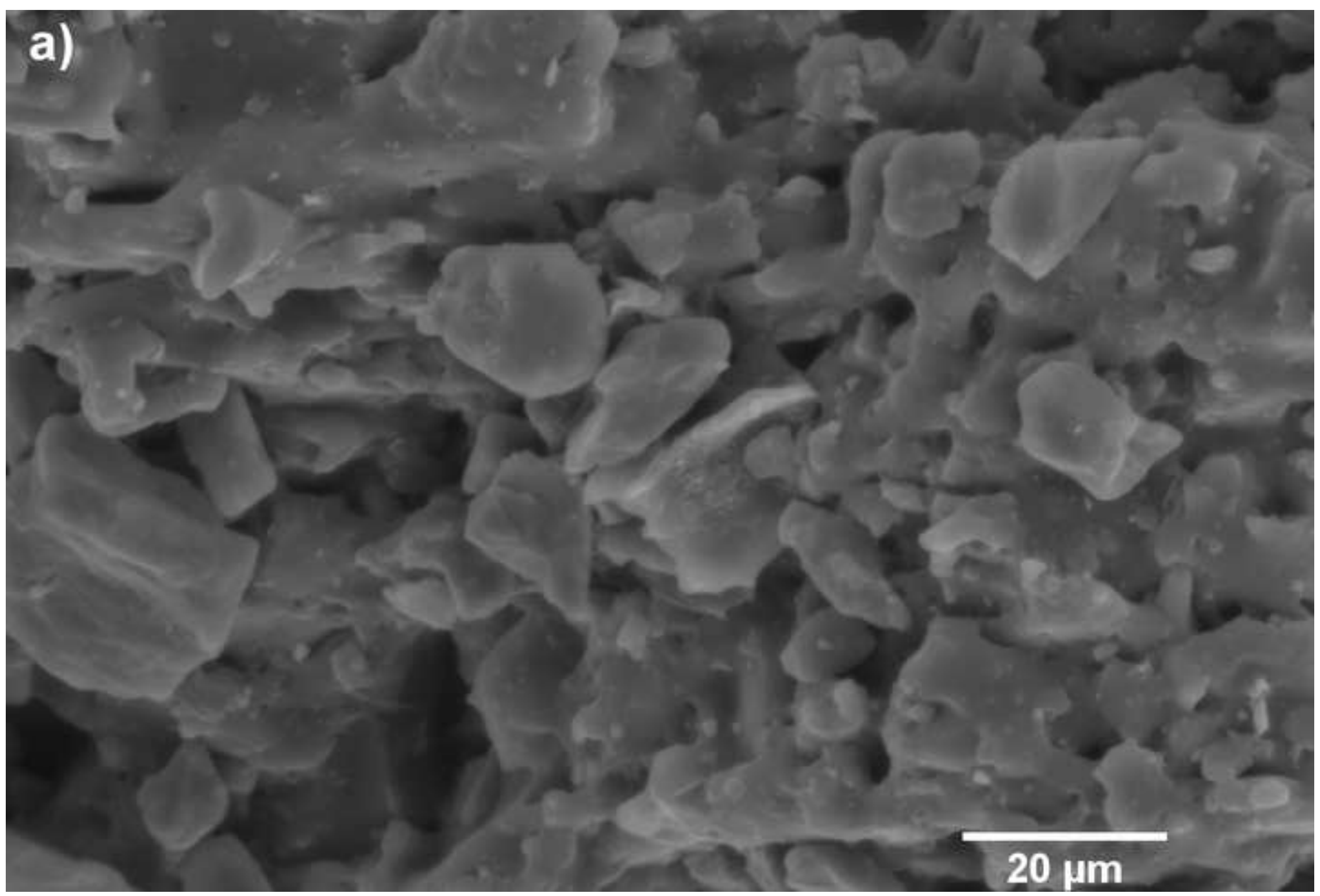

Fig. 5:SEM micrograph of guayule rubber composites 


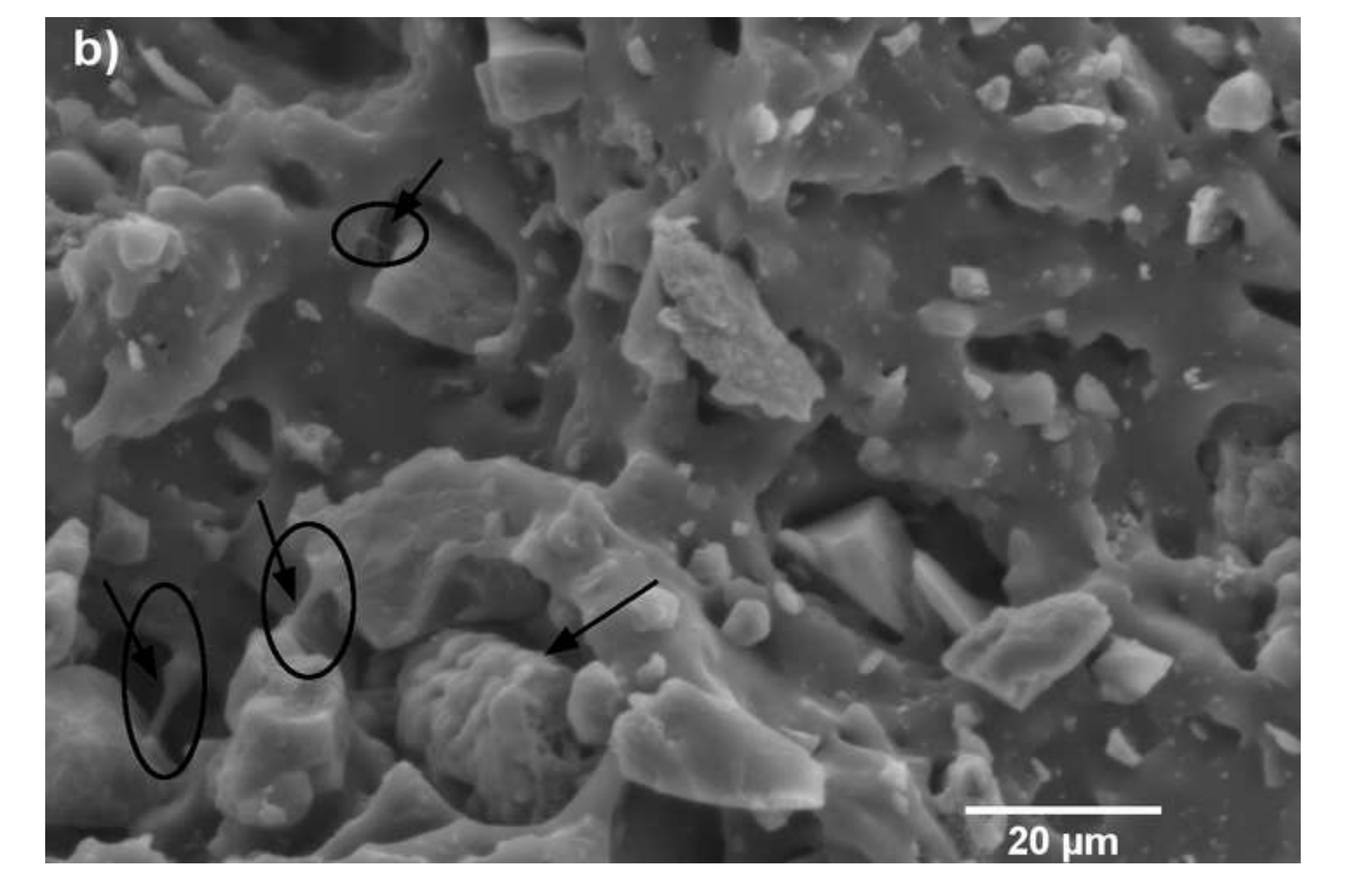

Fig. 5:SEM micrograph of guayule rubber composites

(1)
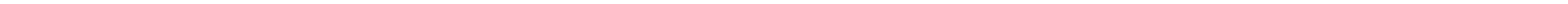


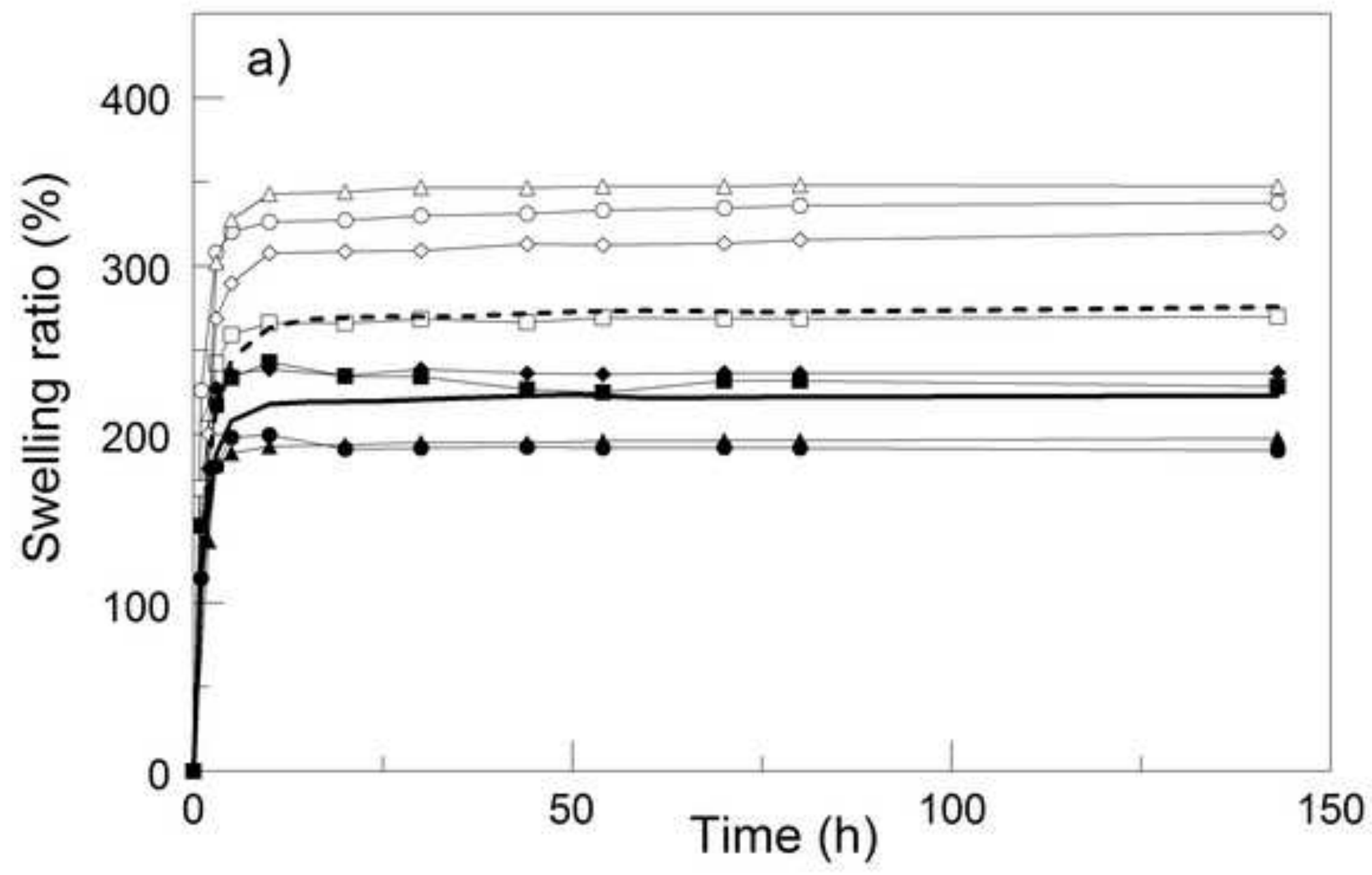




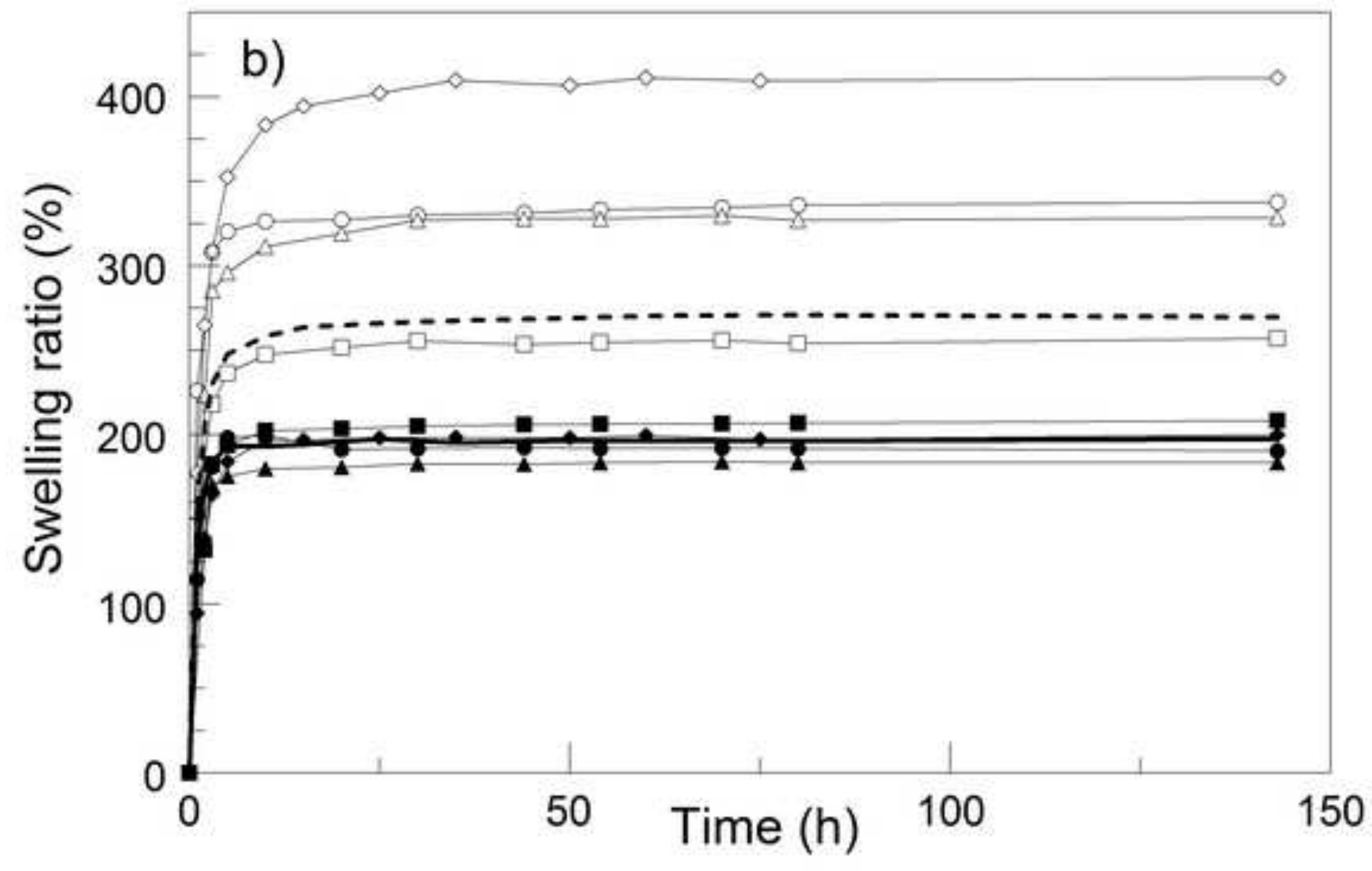


Figure 7

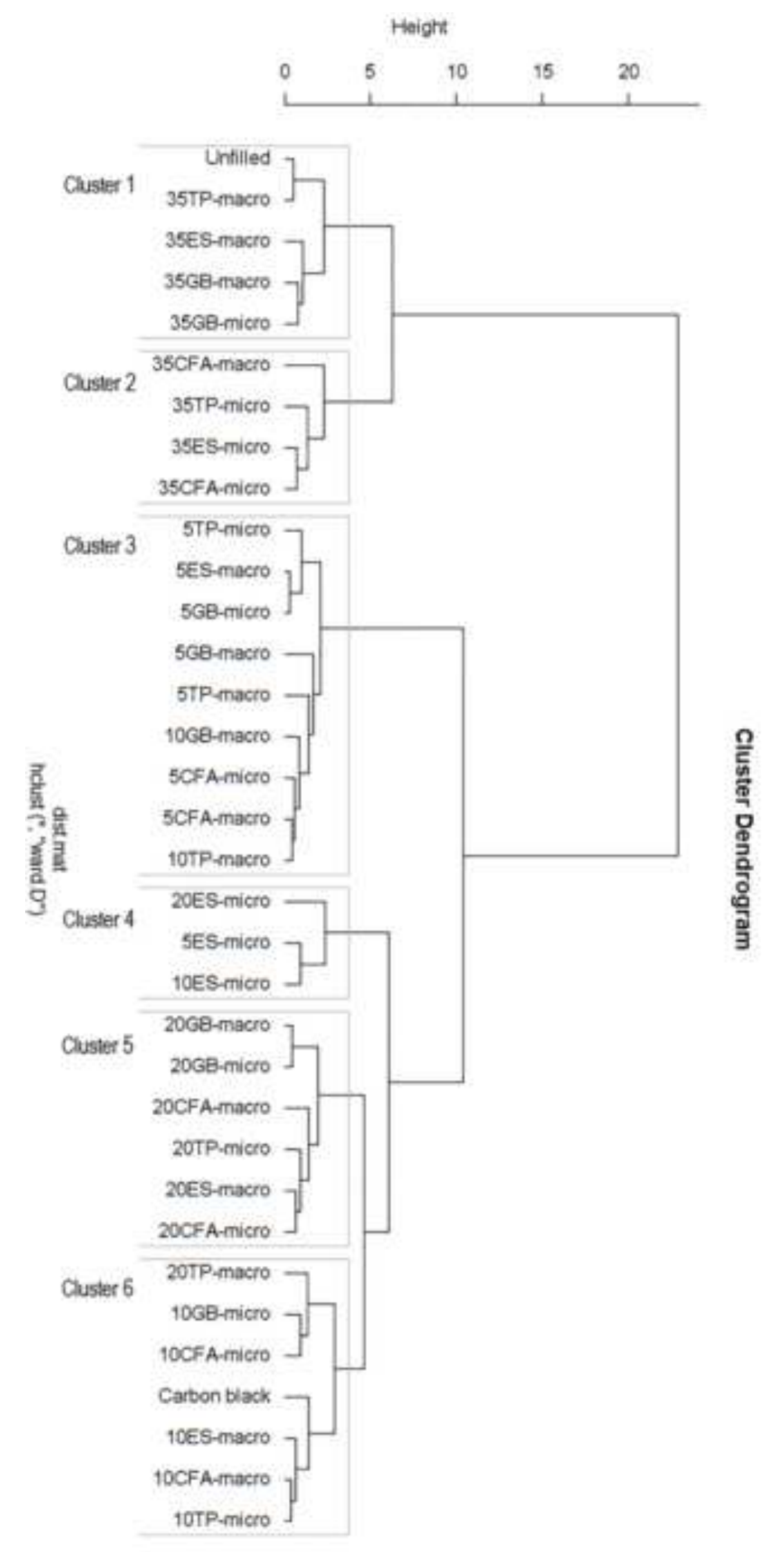

7 

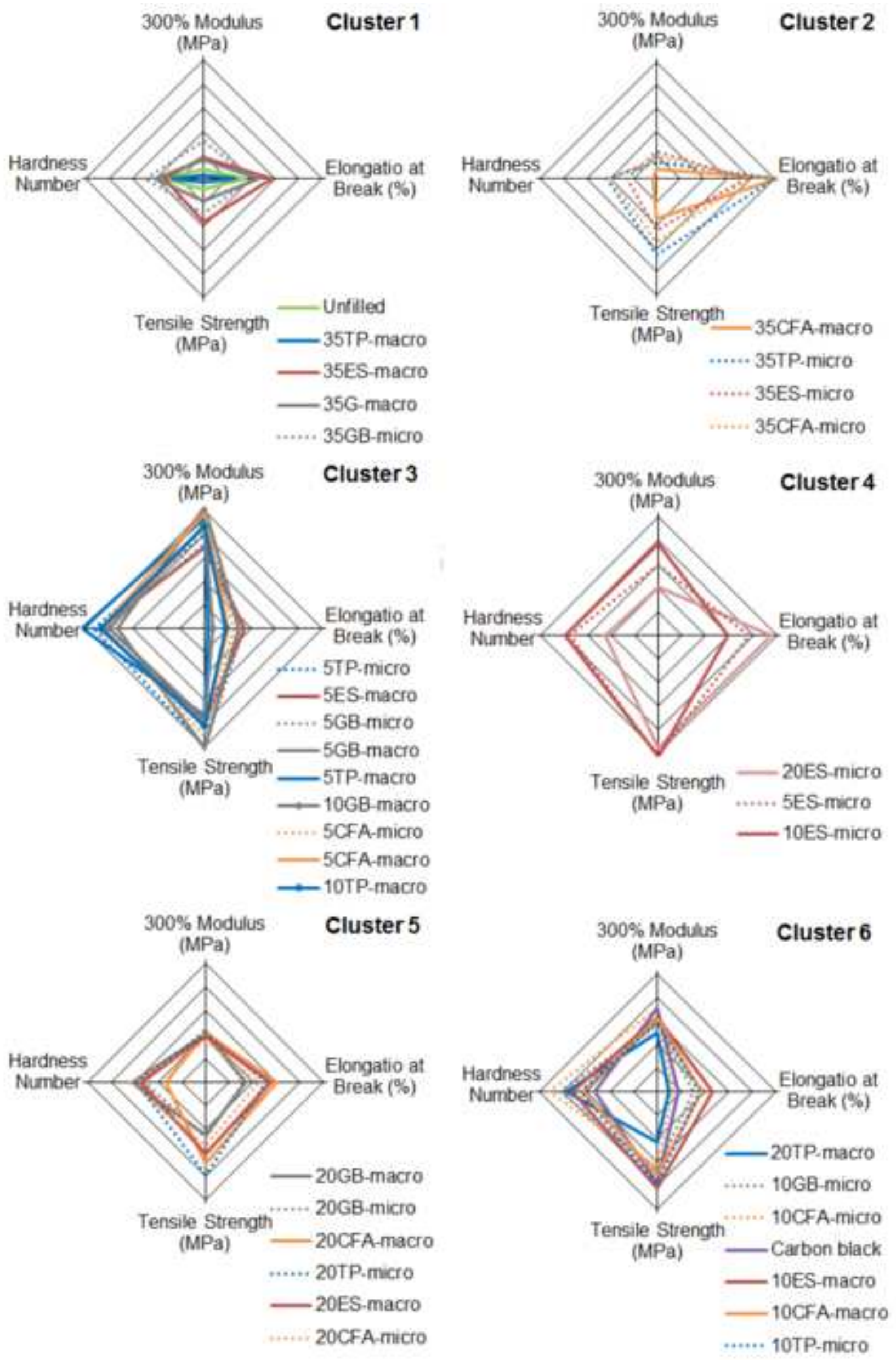
Table 1: Compounding formulations used to prepare guayule rubber composites.

\begin{tabular}{|c|c|c|c|c|c|}
\hline Material & \multicolumn{5}{|c|}{ Quantity (phr) } \\
\hline Guayule rubber & \multicolumn{5}{|l|}{100} \\
\hline Carbon black & 35 & 30 & 25 & 15 & 0 \\
\hline Filler & 0 & 5 & 10 & 20 & 35 \\
\hline Sulfur & \multicolumn{5}{|l|}{3.5} \\
\hline Zinc Oxide & \multicolumn{5}{|c|}{5} \\
\hline Butyl benzothiazole sulfonamide (TBBS) & \multicolumn{5}{|c|}{0.75} \\
\hline Stearic acid & \multicolumn{5}{|l|}{1} \\
\hline
\end{tabular}

Table 2: Filler bulk densities.

\begin{tabular}{|l|l|l|l|}
\hline Filler & Size & Density $\left(\mathbf{g} / \mathbf{c m}^{\mathbf{3}}\right)$ & Means comparison* \\
\hline Carbon black & & $0.42 \pm 0.01$ & E \\
\hline CFA & macro & $0.74 \pm 0.02$ & B \\
\hline CFA & micro & $0.57 \pm 0.01$ & D \\
\hline GB & macro & $0.53 \pm 0.02$ & D \\
\hline GB & micro & $0.36 \pm 0.07$ & E \\
\hline ES & macro & $1.32 \pm 0.02$ & A \\
\hline ES & micro & $0.79 \pm 0.05$ & B \\
\hline TP & macro & $0.69 \pm 0.02$ & BC \\
\hline TP & micro & $0.60 \pm 0.02$ & CD \\
\hline
\end{tabular}

* Multiple means comparison Tukey-Kramer test, at a significance level $\alpha$ of 0.05 . Samples that do not share a common letter are significantly different. 
Table 3: Swelling ratio at equilibrium and crosslink density $\left(v_{\mathrm{e}}\right)$ of guayule rubber composites

\begin{tabular}{|c|c|c|}
\hline Sample* & $\begin{array}{l}\text { Swelling ratio at } \\
\text { equilibrium }(\%)\end{array}$ & $\begin{array}{l}V_{e} \\
\left.\mathrm{~mol} / \mathrm{cm}^{3}\right)\end{array}$ \\
\hline Unfilled compound (no filler) & 337.71 & 0.395 \\
\hline 35 phr carbon black & 199.69 & 1.151 \\
\hline 35 phr tomato peel micro & 269.98 & 0.622 \\
\hline $20 \mathrm{phr}$ tomato peel micro & 262.95 & 0.656 \\
\hline $10 \mathrm{phr}$ tomato peel micro & 244.98 & 0.758 \\
\hline 5 phr tomato peel micro & 243.02 & 0.770 \\
\hline 35 phr tomato peel macro & 257.00 & 0.687 \\
\hline 20 phr tomato peel macro & 238.05 & 0.803 \\
\hline 10 phr tomato peel macro & 216.80 & 0.973 \\
\hline 5 phr tomato peel macro & 208.53 & 1.053 \\
\hline 35 phr carbon fly ash micro & 348.30 & 0.371 \\
\hline $20 \mathrm{phr}$ carbon fly ash micro & 233.76 & 0.834 \\
\hline 10 phr carbon fly ash micro & 211.60 & 1.022 \\
\hline 5 phr carbon fly ash micro & 197.62 & 1.175 \\
\hline 35 phr carbon fly ash macro & 329.58 & 0.415 \\
\hline 20 phr carbon fly ash macro & 236.22 & 0.816 \\
\hline 10 phr carbon fly ash macro & 200.05 & 1.146 \\
\hline 5 phr carbon fly ash macro & 184.08 & 1.359 \\
\hline 35 phr guayule bagasse micro & 320.20 & 0.440 \\
\hline 20 phr guayule bagasse micro & 320.03 & 0.440 \\
\hline 10 phr guayule bagasse micro & 244.22 & 0.763 \\
\hline 5 phr guayule bagasse micro & 236.82 & 0.812 \\
\hline 35 phr guayule bagasse macro & 411.41 & 0.266 \\
\hline 20 phr guayule bagasse macro & 265.39 & 0.644 \\
\hline 10 phr guayule bagasse macro & 217.60 & 0.965 \\
\hline 5 phr guayule bagasse macro & 200.25 & 1.144 \\
\hline 35 phr eggshell micro & 275.62 & 0.596 \\
\hline 20 phr eggshell micro & 235.78 & 0.819 \\
\hline 10 phr eggshell micro & 193.35 & 1.229 \\
\hline 5 phr eggshell micro & 223.77 & 0.912 \\
\hline 35 phr eggshell macro & 270.79 & 0.618 \\
\hline 20 phr eggshell macro & 221.43 & 0.931 \\
\hline 10 phr eggshell macro & 199.51 & 1.153 \\
\hline 5 phr eggshell macro & 197.81 & 1.173 \\
\hline
\end{tabular}

*Total amount of filler (carbon black plus waste-derived filler), in all samples was $35 \mathrm{phr}$. 